
Printed in the United States of America. Available from National Technical Information Service
U.S. Department of Commerce 5285 Port Royal Road, Sprngfield, Virginia 22161
Price: Printed Copy $\$ 525$; Microfiche $\$ 3.00$

This report was prepared as an account of work sponsored by an agency of the Unted States Government Nether the Unted States Government nor any agency thereof, nor any of their employees, contractors, subcontractors, or their employees, makes any warranty, express or implied, nor assumes any legalliability or responsibilty for any thro party's use or the results of such use of any intomation, apparatus, product or process disclosed in this report, nor represents that its use by such throd party would notunfrnge privately owned rights 


\section{DISCLAIMER}

This report was prepared as an account of work sponsored by an agency of the United States Government. Neither the United States Government nor any agency Thereof, nor any of their employees, makes any warranty, express or implied, or assumes any legal liability or responsibility for the accuracy, completeness, or usefulness of any information, apparatus, product, or process disclosed, or represents that its use would not infringe privately owned rights. Reference herein to any specific commercial product, process, or service by trade name, trademark, manufacturer, or otherwise does not necessarily constitute or imply its endorsement, recommendation, or favoring by the United States Government or any agency thereof. The views and opinions of authors expressed herein do not necessarily state or reflect those of the United States Government or any agency thereof. 


\section{DISCLAIMER}

Portions of this document may be illegible in electronic image products. Images are produced from the best available original document. 
Contract No. W-7405-eng-26

NUCLEAR FUEL AND WASTE PROGRAMS

This report was propount of work This report was prepared as an account of we the United States nor the Unted States Department of Energy, nor any of thesr employees, nor any of their contractors, subcontractors, or therr employees, makes any warranty, express or impled, or assumes any legat hability or responsiblity for the accutacy, conpieteness or usefulness of anv information, apparatus, product or process disclosed or fepresents that its use would not infromge privately owned nghts

\title{
SOL-GEL SPHERE-PAC ACTIVITIES FOR THE \\ FUEL REFABRICATION AND DEVELOPMENT PROGRAM \\ QUARTERLY PROGRESS REPORT FOR PERIOD ENDING DECEMBER 31, 1977
}

A. L. Lotts, Program Director

R. L. Beatty, Program Manager

Date Published: March 1979

NOTICE This document contains information of a preliminary nature. It is subject to revision or correction and therefore does not represent a final report.

\author{
OAK RIDGE NATIONAL LABORATORY \\ Oak Ridge, Tennesse 37830 \\ operated by \\ UNION CARBIDE CORPORATION \\ for the \\ DEPARTMENT OF ENERGY
}


$\gamma$

:

- 
SUMMARY . . . . . . . . . . . . . . . . . . . v v

1. INTRODUCTION . . . . . . . . . . . . . . . . 1

2. SOL-GEL SPHERE-PAC FUEL - TECHNOLOGY STATUS AND

PERFORMANCE ASSESSMENT - SUBTASK 502 . . . . . . . . . 3

3. SOL PREPARATION - SUBTASK 510 .............. 5

3.1 INTRODUCTION ................ 5

3.2 SOLEX SOL PREPARATION . . . . . . . . . . . . 5

3.3 SOL PREPARATION BY PARTIAL NEUTRALIZATION OF
NITRATE SOLUTION . . . . . . . . . . . 10

3.4 PREPARATION OF URANYL NITRATE BROTHS . . . . . . . . 11

3.5 REFERENCES . . . . . . . . . . . . . 12

4. SPHERE FORMING - SUBTASK 520 . . . . . . . . . . 13

4.1 INTRODUCTION . . . . . . . . . . . . . 13

4.2 SELECTION OF TEST PROCEDURE FOR EXTERNAL GELATION • • • 14

4.3 EXTERNAL GELATION RESULTS FOR ThO 2 . . . . . . . 18

4.4 EXTERNAL GELATON RESULTS FOR $\mathrm{ThO}_{2}-\mathrm{UO}_{3}$......... 18

4.5 EXTERNAL GELATION RESULTS FOR UO $\mathrm{UO}_{3}$. . . . . . . . . 22

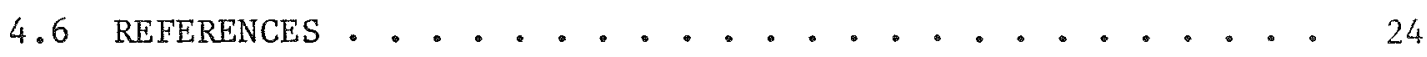

5. WASHING AND DRYING - SUBTASK 530 . . . . . . . . 25

5.1 INTRODUCTION . . . . . . . . . . 25

5.2 SMALL-BATCH DRYING . . . . . . . . . . . 25

5.3 CONTINUOUS DRYING . . . . . . . . . . . . 26

6. SINTERING - SUBTASK 540 .............. 27

6.1 INTRODUCTION . . . . . . . . . . . . . . 27

6.2 PROCEDURES AND EQUIPMENT . . . . . . . . . . . 27

6.3 PARTICLE CHARACTERIZATION . . . . . . . . . . 29

6.4 RESULTS OF SINTERING EXPERIMENTS ............ 31

6.5 REFERENCES .................... 37

7. FUEL ROD LOADING - SUBTASK 550 . . . . . . . . . . 39

7.1 INTRODUCTION . . . . . . . . . . . . . 39

7.2 LITERATURE REVIEW . . . . . . . . . . . . 40 
7.3 LOADING APPROACHES . . . . . . . . . . . 41

7.4 LOADING STUDIES . . . . . . . . . . . 43

7.5 CONTINUING DEVELOPMENT . . . . . . . . . . . 45

8. FUEL ROD INSPECTION - SUBTASK 560 . . . . . . . . . 49

8.1 INTRODUCTION . . . . . . . . . . . . 49

8.2 LOADING LEVEL AND DENSITY DETERMINATION . . . . . . 49

8.3 FUEL ROD INSPECTION INSTRUMENTATION . . . . . . . 51 
SUMMARY

Development of refabrication processes for proliferation-resistant fuels for thermal reactors was initiated in fiscal year 1978 under the Fuel Refabrication and Development Program managed for the Department of Energy by Battelle-Pacific Northwest Laboratories. Within the overall Program scope, development of the sol-gel sphere-pac process for remote refabrication of highly-gamma-active fuels was assigned to the Oak Ridge National Laboratory (ORNL). Activities at ORNL fall under the Task 500 category and have been subdivided into seven work areas or subtasks for conducting the development work proposed for fiscal year 1978. These are:

Subtask 502, Sol-Gel Sphere-Pac Fuel Technology Status and Performance Assessment

Subtask 510, Sol Preparation

Subtask 520, Sphere Forming

Subtask 530, Washing and Drying

Subtask 540, Sintering

Subtask 550, Fuel Rod Loading

Subtask 560, Fuel Rod Inspection

Work summarized below represents the development status attained in the initial quarter of work on the program.

Sol-Gel Sphere-Pac Fuel Technology Status and Performance Assessment (Subtask 502)

An early technology status and performance assessment was included as an important part of this program to provide a state-of-technology basis to help guide the development work. Work during the quarter consisted of performing literature surveys and visiting European laboratories actively involved in sol-gel sphere-pac work. From these and additional literature searching and current development work, a technology status and irradiation performance assessment report will be written later in the fiscal year. 


\section{Sol Preparation (Subtask 510)}

Sol preparation was accomplished utilizing four methods during the quarter. Thoria and Th-U sols were prepared by a batch solvent extraction process in which nitric acid is extracted from nitrate solutions. Thoria sols were also prepared by partial neutralization of nitrate solutions, and Th sol prepared by hydrothermal denitration of thorium nitrate was purchased to study its sphere forming characteristics. Uranium "broths" were prepared by addition of an organic polymer to urany1 nitrate solutions. The polymer provides a gel support structure during precipitation. Polymers utilized included polyvinyl alcohol (PVA) and hydroxypropyl methyl cellulose (K4M). The sphere forming characteristics of the above sols are described below.

\section{Sphere Forming (Subtask 520)}

Three processes for preparing spheres via sol-gel processes are well known. These are water extraction and external and internal chemical gelation. Studies during this quarter focused on sphere preparation by external gelation which initially appeared to be the simplest process.

A simple laboratory procedure for preparing microspheres by external gelation was developed. This consisted of forming drops in air and effecting gelation by passage through ammonia gas and into aqueous ammonium hydroxide. Over 150 laboratory gelation tests were conducted in this manner.

Thoria sols prepared by all four methods described above were successfully formed into good dried gel spheres by external gelation. All mixed oxide sols of thorium and uranium (regardless of sol preparation method) gave weak gels which generally resulted in smashed, ruptured or distorted spheres. However, mixed oxide sols prepared by partial neutralization gave promising results and merit further testing at a later time.

Preparation of microspheres from uranium-containing broths using external gelation gave poor results (although literature reports for such preparation indicate positive results). Therefore, a combination of 
external and internal gelation was attempted. Results of this test were not promising but did indicate that internal gelation alone may be more promising. On this basis, work next quarter will focus on internal gelation.

Washing and Drying (Subtask 530)

Washing and drying for all of the development tests described above were limited to simple procedures with little attention to efficiency or determination of minimum requirements. Many batches of $\mathrm{ThO}_{2}$ and several batches of $\mathrm{UO}_{2}$ microspheres were successfully washed and dried in preparation for sintering.

A continuous, multiple-stage moving-bed type wash column for largerscale washing was designed, fabricated and tested for solids movement.

In order to dry sol-gel spheres without local overheating, use of a moving-belt dryer is indicated. During this quarter, specifications were prepared and bids requested for the purchase of such a dryer.

Sintering (Subtask 540)

During this quarter, progress was made in all four areas of the sintering program: (1) assessment of published literature, (2) characterization of feed and final material, (3) sintering experimentation, and (4) interaction with sol-gel preparation subtasks to allow optimization of feed materials. Concerning item 1, the most relevant of more than 300 references were collected and are being evaluated. Equipment for performing sintering experiments was identified and put into use, or is being readied for use. Procedures were developed for characterizing both feed and final material. Preparation of larger furnaces for sintering large batches of spheres under controlled atmosphere is underway.

Several batches of $\mathrm{ThO}_{2}$ sol-gel microspheres were sintered in air to greater than $99 \%$ of theoretical density at temperatures of 1350 to $1450^{\circ} \mathrm{C}$.

Fuel Rod Loading (Subtask 550)

Work during the quarter was focused in the following areas: literature review, selection of loading approach and loading studies. A survey of all published literature concerning packed particle nuclear 
fuel preparation by both sphere-pac and vibratory-compaction techniques was conducted. A review of loading approaches resulted in selecting the single infiltration of a fine fraction into a pre-blended restrained bed of two coarse fractions as the method to be developed for this program. Required fuel pin smear densities can be obtained in this manner.

Loading studies this quarter gave the following results. A laboratoryscale loading system was constructed to study the effects of various sphere sizes and size distribution on the loading processes. A blending technique was developed for mixing two sizes of coarse spheres in 6-8 in. bed heights. Drop tests to assess sphere breakage during loading of full length LWR fuel pins indicated that sphere breakage is not a problem.

In addition to developing methods for performing parametric studies, techniques for loading fuel pins up to $12 \mathrm{ft}$ in length must be developed. Study of requirements and operating criteria for such equipment was initiated and a conceptual flowsheet developed. Work was begun to design and test methods for pneumatically transferring the fine fraction and for dispensing all three size fractions. Vendors were contacted to determine the cost and availabiltiy of large vibrators, since the 1iterature study indicated these may be required for full-scale fuel pin loading.

Fuel Rod Inspection (Subtask 560)

Development of a nondestructive high precision technique for measuring heavy metal density and homogeneity in sphere-pac fuel pins is required. During the quarter, criteria for a gamma attenuation device to serve this function were developed and fabrication of a laboratory-scale system was begun. An experiment was performed verifying the optimum photon energy necessary and Lutetium-117m was selected as the optimum gamma source. The instrumentation and control system for this equipment and necessary parts were ordered. 


\section{INTRODUCTION}

\section{R. E. Norman}

In support of our national nuclear energy policy an Integrated Fuel Cycle Development Program has been launched by the Nuclear Power and Development Division of the Department of Energy. The purpose of this program is to assess and develop nuclear fuel cycle technology for thermal reactors which offers increased proliferation resistance of the fissile materials at all stages of the fuel cycle. Within the overall program the lead responsibility for Fuel Refabrication and Development has been assigned to Battelle's Pacific Northwest Laboratories (PNL).

To achieve a proliferation-resistant fuel cycle, a technical approach employing various combinations of uranium, thorium, and plutonium has been proposed, including:

coprocessed $\mathrm{UO}_{2}-\mathrm{Pu}_{2}$,

highly radioactive (fission-product-"spiked") Pu-containing fuel, and denatured ${ }^{233} \mathrm{UO}_{2}-\mathrm{ThO}_{2}$.

Utilization of fission product contaminated fuel or denatured ${ }^{23} \mathrm{U}$ fuel will require remote handing due to the high level of gamma activity. Therefore, fuel cycle technology development which is readily adaptable to remote refabrication is of great interest to this program.

A promising technology in this regard is the sol-gel sphere-pac process which was in fact originally developed with remote application in mind. The major effort in the development of the sol-gel sphere-pac refabrication option has been assigned to ORNL. The purpose of this part of the Fuel Refabrication and Development Program is to develop processes and equipment necessary to qualify sphere-pac technology at a level adequate for design of a reference commercial-scale facility and to develop an irradiation test data base adequate for licensing sphere-pac fuel for use in commercial power reactors.

The sol-gel sphere-pac fuel concept is notable in its direct applicability to all proposed fuel compositions. In addition, it is particularly advantageous for remote operation because it converts $U$, Th, and Pu nitrate solutions to dense oxide spheres without powder 
preparation and handling or precise grinding required by pellet manufacture. This results in lower radioactive dose rates to operating and maintenance personnel, easier equipment maintenance, better material accountability, and less scrap generation. Limited irradiation data presently available indicate that sphere-pac fuel performs as well as pellet fuel. On these bases gel-sphere-pac process development and irradiation testing are planned to receive major emphasis for mid-term (1990-95) employment of proliferation-resistant fuel cycles dealing with high activity fuels. For near-term (1985-90) use of "clean" coprocessed $\mathrm{UO}_{2}-\mathrm{PuO}_{2}$, sphere-pac fuel has been proposed as a backup to pellet fuel.

During FY-78, development of the ge1-sphere-pac process is focused in the areas of sol or broth preparation, dense sphere preparation and development of sphere-pac loading technology. The FY-78 program includes preparation of $\mathrm{ThO}_{2}$ spheres for sphere-pac loading studies and development of flowsheets for $\mathrm{UO}_{2}$ preparation. 


\section{SOL-GEL SPHERE-PAC FUEL - TECHNOLOGY STATUS AND PERFORMANCE ASSESSMENT - SUBTASK 502}

\section{R. L. Beatty}

While the present work aimed at development of a sol-gel sphere-pac refabrication option marks the beginning of a new program, an extensive technological base exists in this area. Relevant technology is available from an earlier U.S. program for development of sol-gel sphere-pac oxide fuel for FBRs, 1 current foreign programs directed to development of ge1-sphere-pac fuel for both LWRs and FBRs, and domestic and foreign programs for development of HTGR fuel.

To take full advantage of the existing technology, an assessment of the status of sol-gel and sphere-pac fabrication technology and spherepac fuel irradiation performance data was identified as an early requirement. The assessment is needed to guide the initial fabrication development work, to provide a base for planning an irradiation test program, and for use in developing an overall Fuel Refabrication and Development Program Plan.

Work this quarter included conducting surveys of available literature in all relevant areas and visiting European laboratories engaged in sol-gel and sphere-pac work. The visits were concerned primarily with sol-gel technology, with detailed discussions on sphere-pac technology and irradiation performance planned for future visits.

The documentation and assessment of the technology status will be carried out during the next two quarters and a separate report, "So1-Ge1 Sphere-Pac Fuel Technology Status and Performance Assessment" will be prepared.

\section{REFERENCE}

1. Fast Breeder Reactor Oxide Fuels Development - Final Report, compiled by A. L. Lotts, ORNL-4901 (November 1973). 
-

- 
3. SOL PREPARATION - SUBTASK 510

P. A. Haas, R. D. Spence, R. D. Author, R. C. Lovelace, and K. E. Sullivan

\subsection{INTRODUCTION}

The preparation of sol is a critical step in the operation of any sol-gel process. A colloidal dispersion is thermodynamically unstable and many of the compositions used are chemically unstable. Therefore, the sol must be described by the recipe used for preparation; chemical and physical measurements do not give a unique specification.

For the current program, sols have been prepared by four procedures to study the relative merits of the preparation processes and their suitability for gelation. The four preparation procedures were:

1. solvent extraction of $\mathrm{HNO}_{3}$ from $\mathrm{Th}\left(\mathrm{NO}_{3}\right)_{4}$ or $\mathrm{Th}\left(\mathrm{NO}_{3}\right)_{4}-\mathrm{UO}_{2}\left(\mathrm{NO}_{3}\right)_{2}$ solutions,

2. partial neutralization of $\mathrm{Th}\left(\mathrm{NO}_{3}\right)_{4}$ or $\mathrm{Th}\left(\mathrm{NO}_{3}\right)_{4}-\mathrm{UO}_{2}\left(\mathrm{NO}_{3}\right)_{2}$ solutions by $\mathrm{NH}_{4} \mathrm{OH}$ to controlled final pH values,

3. preparation of uranyl nitrate "broths" with uranyl ion in solution and organic polymer as a thickener or gelation agent, and

4. hydrothermal denitration of $\mathrm{Th}\left(\mathrm{NO}_{3}\right)_{4}$ to $\mathrm{ThO}_{2}$ which is dispersed in dilute $\mathrm{HNO}_{3}$. (The $\mathrm{ThO}_{2}$ sol was purchased from General Atomic Co.). Experimental results for the first three preparation procedures are described in the following sections. The results of gelation tests of al1 four types of sols are reported in the results for sphere forming (Subtask 520). The process details for the General Atomic Co. pilot plant (0.1 ton/day $\mathrm{ThO}_{2}$ capacity) are proprietary and only gelation results are reported for this $\mathrm{ThO}_{2}$ sol.

\subsection{SOLEX SOL PREPARATION}

At the start of this project, an existing solvent extraction system for denitrating $\mathrm{UO}_{2}\left(\mathrm{NO}_{3}\right)_{2}$ solutions was in use for the resin loading portion of the HTGR fuel recycle process.1,2 Small changes in the process lines allow operation of batch flowsheets similar to the continuous flowsheets previously used to produce thorium-uranium sols by solvent 
extraction (Solex). 3 Tie lines were used so the equipment could be used for both resin loading work and sol-gel work. The block diagram in Fig. 3.1 illustrates the batch operation for producing Solex sols. (Note that the evaporation step serves the same purpose as "digestion" in the literature.) This equipment was used to produce several sols and to test different Solex operating procedures.

The sols prepared by the Solex method are summarized in Table 3.1. Run No. 101 was used to generate a pure thoria sol and to gain operating experience with different operating parameters with relation to the condition of the sol. Using the batch method, the final sol conditions could be approached as slowly as desired. Run No. 102 produced the first $\mathrm{ThO}_{2}-\mathrm{UO}_{3}$ sol. In these first two runs, the extraction process was taken as far as possible without evaporation (and digestion). Then evaporation was initiated, resulting in release of more $\mathrm{HNO}_{3}$ and extraction was continued.

The experience gained in the first two runs was used to control the progress of run No. 103 in which the start of evaporation was based on sol pH rather than a leveling off of extraction. In the next run (No. 104), a different operating procedure was used to produce a different sol. Previous workers had shown that the gel point for sols occurred at higher concentrations as the relative amount of nitrate ion increased $\left(\mathrm{NO}_{3}-\right.$ metal ratio) (Fig. 3.2).4 Since higher metal concentrations would supposedly be beneficial for production of large microspheres, the final $\mathrm{NO}_{3}{ }^{-}$/metal ratio for the sol in this run was to be high. As for the difference in the operating procedure, the evaporator was utilized from the start and the metal concentration controlled within the $0.5 \mathrm{M}$ to $0.6 M$ range. The change in the operating procedure worked fine, but the sol precipitated while being concentrated by evaporation. Extrapolation of the curve in $\mathrm{Fig} .3 .2$ to the $\mathrm{NO}_{3}{ }^{-}$/metal ratio of interest $(0.7)$ indicated that the sol should have been stable well above $5 M$, but the sol precipitated at a total metal concentration between 1.1 and $1.4 \mathrm{M}$. Analysis of the supernatant indicated that the precipitate consisted of thorium. Similar behavior was observed for run No. 105. The $\mathrm{NO}_{3}-$ /metal ratio in this case was 0.9 . During concentration of the sol 
Fig. 3.1. Batch Preparation of $\mathrm{ThO}_{2}-\mathrm{UO}_{3} \mathrm{Sol}$ by Amine Extraction (Solex).

ORNL DWG 77.2254

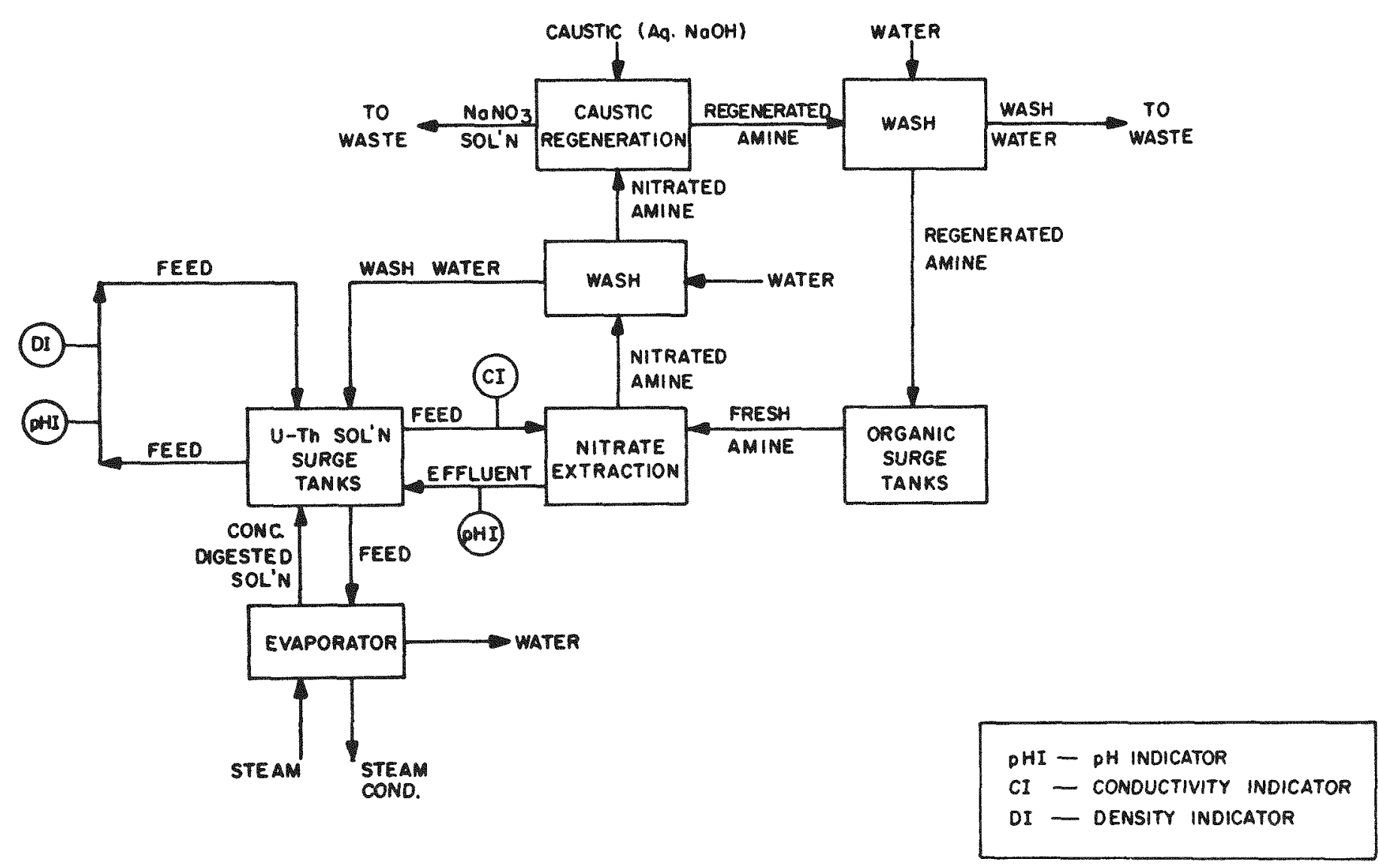


Table 3.1. Properties of Solex Sols.

\begin{tabular}{|c|c|c|c|c|c|c|c|c|}
\hline & Sol & $\begin{array}{c}\text { Nominal } \\
\% \mathrm{U}\end{array}$ & $\begin{array}{l}\text { Th } \\
(M)\end{array}$ & $\begin{array}{c}U \\
(M)\end{array}$ & $\begin{array}{l}\mathrm{No}_{3} \\
(M)\end{array}$ & $\begin{array}{c}(\mathrm{Th}+\mathrm{U}) \\
(M)\end{array}$ & $\mathrm{NO}_{3} /(\mathrm{Th}+\mathrm{U})$ & $\underset{(M)}{\operatorname{Gelation} \text { Point }}$ \\
\hline 101 & & 0 & 0.75 & 0.006 & 0.24 & 0.76 & 0.31 & $4.5-5.6$ \\
\hline \multirow[t]{3}{*}{102} & A & 30 & 0.32 & 0.14 & 0.11 & 0.46 & 0.24 & \\
\hline & B & & 1.19 & 0.47 & 0.41 & 1.66 & 0.25 & \\
\hline & $\mathrm{C}$ & & 1.62 & 0.71 & 0.54 & 2.33 & 0.23 & $3.6-4.1$ \\
\hline \multirow[t]{3}{*}{103} & A & 30 & 0.41 & 0.19 & 0.11 & 0.60 & 0.18 & \\
\hline & B & & 1.46 & 0.66 & 0.53 & 2.12 & 0.25 & \\
\hline & $\mathrm{C}$ & & 2.03 & 0.94 & 0.743 & 2.97 & 0.25 & \\
\hline \multirow[t]{3}{*}{104} & A & 30 & 0.47 & 0.22 & 0.36 & 0.69 & 0.51 & $1.1-1.4$ (precipitated) \\
\hline & $\mathrm{B}^{\mathrm{a}}$ & & 1.04 & 0.49 & 1.08 & 1.53 & 0.70 & \\
\hline & $\mathrm{c}^{\mathrm{a}}$ & & 1.40 & 0.68 & 1.45 & 2.08 & 0.70 & \\
\hline \multicolumn{2}{|c|}{ Supernatant $\mathrm{C}$} & & 0.12 & 0.68 & 1.10 & 0.80 & 1.40 & \\
\hline \multirow[t]{2}{*}{105} & A & 20 & 0.75 & 0.21 & 0.88 & 0.96 & 0.92 & \\
\hline & $1440^{\mathrm{a}}$ & & 0.93 & 0.26 & 1.06 & 1.19 & 0.89 & 1.2 (precipitated) \\
\hline \multirow{3}{*}{ Supe } & ernatant 1440 & & 0.43 & 0.23 & 0.96 & 0.66 & 1.45 & \\
\hline & B & & 0.86 & 0.24 & 0.33 & 1.10 & 0.30 & \\
\hline & $\mathrm{C}$ & & 1.60 & 0.44 & 0.57 & 2.04 & 0.28 & \\
\hline \multirow[t]{4}{*}{106} & A & 20 & 0.31 & 0.084 & 0.22 & 0.393 & 0.56 & $2.0-2.7^{\mathrm{b}}$ (precipitated) \\
\hline & B & & 0.66 & 0.18 & 0.17 & 0.84 & 0.20 & \\
\hline & $\mathrm{C}$ & & 1.13 & 0.31 & 0.26 & 1.43 & 0.18 & \\
\hline & D & & 1.38 & 0.38 & 0.32 & 1.75 & 0.18 & $6.2-9.3$ \\
\hline \multicolumn{2}{|l|}{107} & 0 & 2.00 & 0.004 & 3.6 & 2.0 & 1.8 & \\
\hline
\end{tabular}

${ }^{a}$ Yellow precipitate formed.

$b_{\text {This }}$ sol precipitated at the stated concentration with thermal evaporation. The sol (106 A) was not exposed to temperatures above $40^{\circ} \mathrm{C}$ and gelled with vacuum evaporation at $\sim 1.0 \mathrm{M}$.

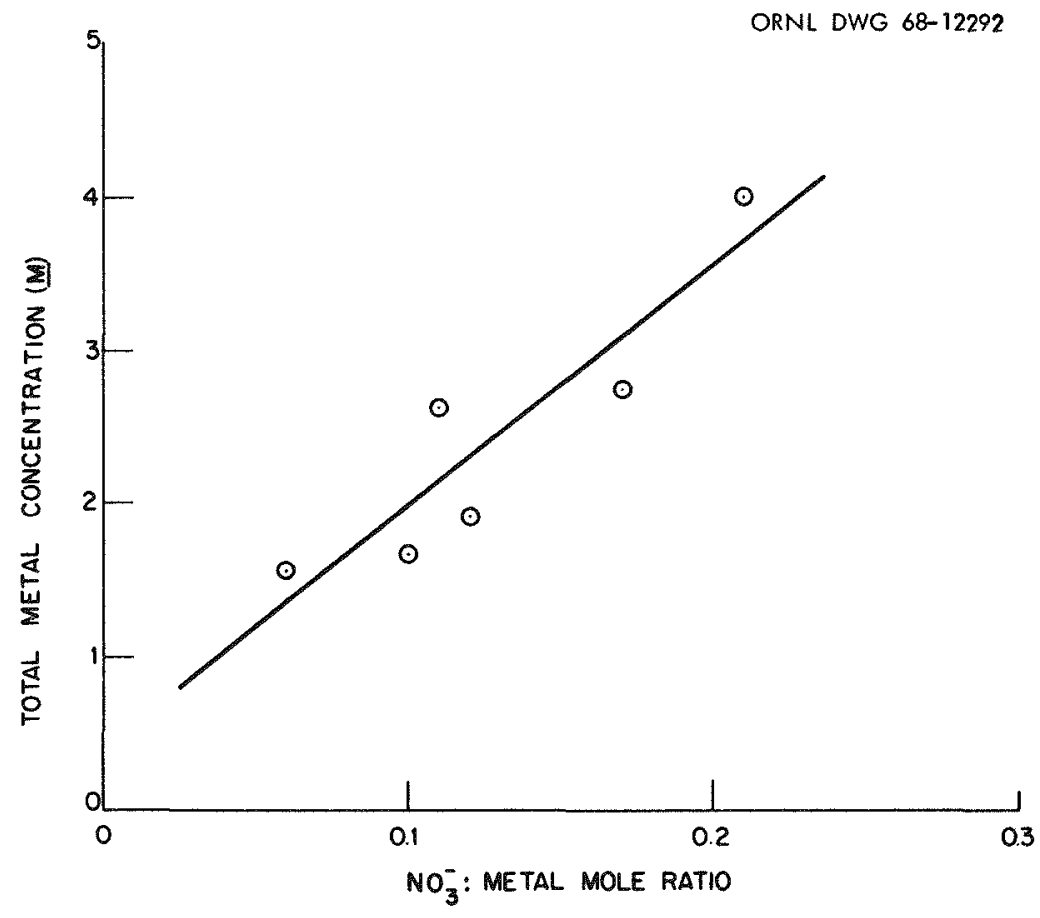

Fig. 3.2. Concentration at which Gelation Occurs for $\mathrm{ThO}_{2}-\mathrm{UO}_{2}$ Sols. 
by evaporation, the effluent from the evaporator was observed to contain thorium precipitate at a concentration of $1.2 \mathrm{M}$. Consequently, the sol was denitrated further while simultaneously evaporating. The resulting sol was stable at $2 \mathrm{M}$ for a $\mathrm{NO}_{3}{ }^{-}$/metal ratio of 0.3 .

In the subsequent run (No. 106), the sol was denitrated as far as possible without evaporation or digestion. A sample was retained at this point (sol 106A) and the rest of the sol denitrated with evaporation and digestion in the usual manner. From Table 3.1, sol 106A has a $\mathrm{NO}_{3}{ }^{-} /$metal ratio of 0.56 . This sol precipitates with thermal evaporation rather than gel in the manner of the two sols discussed above and does so at 2.0 to $2.7 \mathrm{M}$. Aparently, $\mathrm{ThO}_{2}-\mathrm{HO}_{3}$ sols are inherently unstable at high heavy metal concentrations with $\mathrm{NO}_{3}{ }^{-}$/ metal ratios above 0.5 .

The equipment adapted from resin loading had in-line instrumentation for measurement of $\mathrm{pH}$, density, and conductivity. Though the span of conductivities and densities for the sols exceeded the range of these instruments, all three performed well and were helpful in indicating the progress of the denitration (grab sample analysis backed up the in-line analysis). Although $\mathrm{pH}$ was the parameter used for control, the conductivity levels off dramatically as the denitration reaction achieves equilibrium and could be used for control.

Note that none of the above analyses give a direct measure of the amount of nitrate present. Their usefulness lies in the relative changes in value as denitration proceeds and they indicate equilibrium by approaching relatively constant values. Nevertheless, target $\mathrm{NO}_{3}^{-}$/metal ratios were approached with some success using these measurements. Other methods of tracking the nitrate content of the sol were also investigated. One method was to measure the density of the organic amine. The density of the nitrated amine is different from the fresh amine, and by tracking the organic density one could theoretically track the rate of nitrate removal. In practice, the organic phase density is as sensitive to temperature as it is to nitration. Although this problem could be overcome, a better method was sought. A second 
method tried was using a nitrate-specific ion electrode. However, the electrode reading showed no correlation with the analvzed nitrate content of several sol samples. A third possibility not fully tested is to use a spectrophotometer to analyze the sol for nitrate. In the one test conducted, the spectrophotometer gave a nitrate content significantly greater than the analytical results.

All of the sols generated by the Solex runs were digested via evaporation except sol 106A. This sol was purposefully not exposed to high temperatures and was denitrated as far as possible under this limitation. The sol was then concentrated via vacuum evaporation to $1 M$, at which point it gelled. The gel was resuspended by addition of water to form a viscous sol $(0.82 \mathrm{M})$. This sol was tested in an external gelation test $(G T-178)$ and compared favorably with other $\mathrm{ThO}_{2}-\mathrm{UO}_{3}$ sols. Wet gel spheres formed as a consistent soft solid, but were split.

Run 107 was made to prepare a partially denitrated solution equivalent to $\mathrm{Th}(\mathrm{OH})_{2}\left(\mathrm{NO}_{3}\right)_{2}$.

In summary, thoria sols and $\mathrm{ThO}_{2}-\mathrm{UO}_{3}$ sols were prepared using a batch solvent extraction process coupled with a thermosiphon evaporator. Using in-1ine $\mathrm{pH}$ and conductivity meters for contro1, the sols have been prepared with both high $(1.0)$ and low $(0.2) \mathrm{NO}_{3}^{-} /$metal ratios. The high ratio sols cannot be concentrated much above $2 M$ without precipitating thorium. Vacuum evaporation can be used to prepare a $\mathrm{ThO}_{2}-\mathrm{UO}_{3}$ that has not been digested.

\subsection{SOL PREPARATION BY PARTIAL NEUTRALIZATION OF NITRATE SOLUTIONS}

Stable colloidal dispersions or sols can be prepared by controlled addition of $\mathrm{NH}_{4} \mathrm{OH}$ or $\mathrm{NH}_{3}$ to $\mathrm{Th}\left(\mathrm{NO}_{3}\right)_{4}$ solutions. Thorium compounds are precipitated locally at the point of base addition, but the precipitate is dissolved or dispersed rapidly in a well agitated solution at temperatures near boiling. For the initial additions of $\mathrm{NH}_{4} \mathrm{OH}$, the thorium remains as a solution equivalent to mixed compositions, with $\mathrm{Th}(\mathrm{OH})\left(\mathrm{NO}_{3}\right)_{3}$ as an example. As $\mathrm{NH}_{4} \mathrm{OH}$ addition and hot digestion are 
continued, colloidal thoria is produced with nitrate as the peptizing ion. Stable dispersions of thoria sols by this procedure are possible for over $90 \%$ neutralization $\left(\mathrm{NH}_{4} \mathrm{OH} / \mathrm{Th}\right.$ ratios of $\left.>3.6\right)$ if the final $\mathrm{pH}$ does not exceed 4. If these limits are exceeded, a voluminous precipitate is formed which will redisperse only if $\mathrm{HNO}_{3}$ is added. Colloidal dispersions are also possible starting with $\mathrm{Th}\left(\mathrm{NO}_{3}\right)_{4}-\mathrm{UO}_{2}\left(\mathrm{NO}_{3}\right)_{2}$ solutions, but the percent neutralization and final pH allowable decrease as the uranium content increases. Uranyl nitrate by itself does not give stable colloidal dispersions.

Two thoria sols were prepared by addition of concentrated $\mathrm{NH}_{4} \mathrm{OH}$ solution to well agitated $\mathrm{Th}\left(\mathrm{NO}_{3}\right)_{4}$ solutions at about $90^{\circ} \mathrm{C}$. Significant amounts of ammonia were lost as hot vapor and more moles of $\mathrm{NH}_{4}$ OH were used than the moles of nitrate in the solutions. Other observations were as follows:

Sol 21 - Excess $\mathrm{NH}_{4} \mathrm{OH}$ resulted in precipitation and $\mathrm{HNO}_{3}$ was added to give final compositions of about $1.7 \mathrm{M} \mathrm{Th}, 7.8 \mathrm{M} \mathrm{NO}_{3}^{-}$, and $\mathrm{pH}=3.9$. The sol was a very cloudy translucent white.

Sol 58 - The final sol was a slightly hazy, transparent thick liquid of $2.5 \mathrm{MTh}, 10 \mathrm{MNO}_{3}^{-}$, and $\mathrm{pH}=3.5$.

\subsection{PREPARATION OF URANYL NITRATE BROTHS}

Work on the $\mathrm{UO}_{2}$ system has concentrated on "broth" type gelation feeds for $U(V I)$ in which the uranium is present as acid-deficient uranyl nitrate solution. (The sols of $\mathrm{ThO}_{2}, \mathrm{UO}_{2}$, or other metals are colloidal dispersions of hydrated metal oxides.) An organic polymer is added to the broth to provide a gel structure for support during precipitation of the uranium. Other organic compounds or $\mathrm{NH}_{4} \mathrm{NO}_{3}$ are added to modify the viscosity or surface tension of the "sol", the precipitation behavior of uranium, or the polymer behavior. The compositions of individual broths formulated and tested are listed in Sect. 4.4 with the gelation results. The components of the broth (other than reagent grade urea, $\mathrm{HNO}_{3}, \mathrm{NH}_{4} \mathrm{OH}$, and $\mathrm{NH}_{4} \mathrm{NO}_{3}$ ) are listed in Table 3.2 . 
Table 3.2. Materials Used for Preparation of Broths

\begin{tabular}{|c|c|c|c|}
\hline Acronym & Name & Source & Remarks or procedures for use \\
\hline ADUN & $\begin{array}{l}\text { Acid-deficient } \\
\text { uranyl nitrate }\end{array}$ & Oak Ridge, $Y-12$ Plant & $\mathrm{NO}_{3} / \mathrm{U}$ ratio of $1.5 \mathrm{~mole} / \mathrm{mole}$ \\
\hline $\mathrm{UO}_{3}$ & Uranium trioxide & ORNL & Disperse and dissolve in $\mathrm{HNO}_{3}$ at $60^{\circ} \mathrm{C}$ \\
\hline PVA & Polyvinyl alcohol & Aldrich Chemical Company & $\begin{array}{l}\text { Molecular weight } 86,000,100 \% \text { hydrolyzed. } \\
\text { Mix in } \mathrm{H}_{2} \mathrm{O} \text { or solution at } 20-25^{\circ} \mathrm{C} \text { and } \\
\text { agitate at } 80^{\circ} \mathrm{C} \text { for } 2 \mathrm{hr} \text {. }\end{array}$ \\
\hline $\mathrm{K} 4 \mathrm{M}$ & $\begin{array}{l}\text { Hydroxypropyl } \\
\text { methyl cellulose }\end{array}$ & Dow Chemical Company & $\begin{array}{l}\text { Disperse in } \mathrm{H}_{2} \mathrm{O} \text { or solution at } 80-90^{\circ} \mathrm{C} \\
\text { and mix with ice-cold } \mathrm{H}_{2} \mathrm{O} \text { or solution. } \\
\text { Agitate in an ice bath for } 20-40 \mathrm{~min} \text {. }\end{array}$ \\
\hline TFA & $\begin{array}{l}\text { Tetrahydrofurfury } 1 \\
\text { alcohol }\end{array}$ & Aldrich Chemical Company & \\
\hline
\end{tabular}

\subsection{REFERENCES}

1. P. A. Haas, HTGR Fuel Development: Loading of Uranium on Carboxylic Acid Cation-Exchange Resins Using Solvent Extraction of Nitrate, ORNL/TM-4955 (Sept. 1975).

2. P. A. Haas, Resin Based Freparation of HTGR FueZs: Operation of an Engineering-Seale Uranium Loading System, ORNL-5300 (Oct. 1977).

3. A. D. Ryon, B. C. Finney, J. P. McBride, and J. R. Parrott, "Development and Application of Solvent Extraction Processes for the Preparation of $\mathrm{ThO}_{2}-\mathrm{UO}_{3}$ and $\mathrm{UO}_{2}$ Sols," Proc. of the Intemational Solvent Extraction Conf., No. 63, pp. 1142-49, The Hague, Netherlands (Apri1 1971).

4. A. D. Ryon and F. L. Daley, Unit Operations Section Quaterly Progress Report, Juzy - September 1967, p. 78. 
4. SPHERE FORMING - SUBTASK 520

P. A. Haas, R. D. Spence, R. D. Arthur, W. E. Eldridge, and K. E. Sullivan

\subsection{INTRODUCTION}

For sol-gel processes, liquid drops are converted to solid spheres by one of three different methods: (1) extraction of water by an immiscible organic liquid, (2) transfer of ammonia into the drop from an external source such as gas or liquid, and (3) internal generation of ammonia by hydrolysis of an amine by heating. Surface gelation in an $\mathrm{NH}_{3}$ gas has been used to preserve the liquid drop shape for passage through a gas-1iquid interface (see Sect. 4.2), but has not yet been successfully used as the primary mechanism of gelation. The mass transfer inside the liquid drop is too slow to complete gelation during practical free-fall distances. Gelation of liquid drops by gas in a f'uidized or packed bed is not practical. Extraction of $\mathrm{HNO}_{3}$ by organic amines was tested as a mechanism of gelation, but is very slow and not too effective as the nitrate is involved in hydrolysis reactions of the metals.

The experimental studies reported here were all for external gelation with mass transfer of ammonia into the drop. The most typical gelation procedure is described and results are given for the three product compositions tested (gels of $\mathrm{ThO}_{2}, 70 \% \mathrm{Th}-30 \% \mathrm{UO}_{3}$ to $80 \% \mathrm{Th}-20 \% \mathrm{UO}_{3}$, and $\mathrm{UO}_{3}$ ).

These experimental studies were intended to demonstrate the external gelation procedure for the large diameter spheres and the compositions required for sphere-pac fuels; these combinations of results had not been demonstrated previously. The extraction of water into 2-ethyl-1hexanol, as developed at ORNL, did not appear practical for forming large $(800 \mu$ diam) urania spheres. The preparation of small spheres by extraction of water into alcohols does not appear to require further development before operation of a demonstration system. 
External gelation with ammonia was selected for initial testing because the internal gelation requires an additional organic forming 1iquid, additional organic components in the broths, and additional washing requirements to remove these organic additives from the gel. Since the experimental results reveal unexpected process difficulties for external gelation, internal gelation tests and installation of internal gelation equipment have been initiated.

\subsection{SELECTION OF TEST PROCEDURE FOR EXTERNAL GELATION}

The most characteristic feature of external gelation is that mass transfer of ammonia to the surface of the aqueous drop is very fast. Since there is no volume change during gelation, a fast surface gelation by ammonia does not cause cracking and distortion problems corresponding to water extraction. The fast surface gelation is both a big advantage and disadvantage. The advantage is that the gelled surface is formed quickly before the liquid surface can stick or coalesce with another drop or surface. The disadvantage is that the liquid must not be exposed to the ammonia until it has been dispersed into drops and the interfacial tension has drawn the drops into a spherical shape. If a dispersion nozzle is operated in $\mathrm{NH}_{3}$ gas or in a liquid containing $\mathrm{NH}_{4} \mathrm{OH}$, the sol is fixed in irregular shapes before the liquid spheres can form. Therefore, the drops must be formed in a gas or liquid free of ammonia and then exposed to the ammonia.

For all practical applications of external gelation, the gelation is mainly accomplished in a liquid. For large drops, the mass transfer in the drop is slow and only a surface skin is formed for any practical free-fall distance in the gas. For small drops, the large number and varied sizes of the drops tend to result in collisions and clusters during gravity fall of drops from $\mathrm{NH}_{3}$-free gas into $\mathrm{NH}_{3}$. Also, the gel spheres must be washed to remove $\mathrm{NH}_{4} \mathrm{NO}_{3}$ or other solutes so that transfer into an aqueous solution in always necessary.

The external gelation process requires that large 1iquid drops be formed in ammonia-free fluid, and that their surfaces be gelled before the drops reach the surface of the aqueous $\mathrm{NH}_{4} \mathrm{OH}$ solution. At a 
gas-liquid or liquid-liquid interface a liquid drop distorts into a nonspherical shape as a result of the different interfacial tension with the two fluids. If the bottom liquid is $\mathrm{NH}_{4} \mathrm{OH}$ solution, the distorted shape will be fixed by gelation. If the drop is falling through a gas, the impact velocity also is likely to cause splattering or distortion. Finally, osmotic effects from different ionic concentrations can greatly disrupt an interface.

The gentlest procedure for avoiding the interfacial effects is to form the sol drop in an ammonia-free organic phase. As the drop falls freely through the organic phase, the ammonia-free organic is replaced by ammonia-containing organic. After the surface is gelled, the drop is allowed to settle through an organic-aqueous interface into aqueous $\mathrm{NH}_{4} \mathrm{OH}$ solution. This procedure has been reported with ketones or kerosine as the organic phase and can be used with 2-ethy1-1-hexanol.

A simpler, but less gentle, procedure is to form the sol drops in air, and allow them to pass through $\mathrm{NH}_{3}$ gas and then an $\mathrm{NH}_{3}$ gas $-\mathrm{NH}_{4} \mathrm{OH}$ solution interface. Here the surface skin must form very rapidly in the gas and must be tough enough to survive the impact with the liquid. The optimum height of fall through $\mathrm{NH}_{3}$ gas is not easy to estimate as the impact velocity and strength of surface skin both increase with freefall distance.

Since all the water and nitrate in the sol remain in the gelled sphere, careful washing and drying are usually necessary. Osmotic pressure effects can crack or otherwise degrade the gel sphere if the solution concentrations differ greatly from those inside the gel.

The simple procedure and equipment used for over 150 laboratory gelation tests will be described. While some other test systems (including one for gelation in 2-ethy1-1-hexanol using dissolved $\mathrm{NH}_{4} \mathrm{OH}$ were used, al1 the important results were demonstrated in the simple system. The test system shown in Fig. 4.1 was set up in a laboratory hood. A fourliter Pyrex beaker was modified to give a $20 \mathrm{~mm} \times 50 \mathrm{~mm}$ oval hole above the 2.5 liter level. Aqueous $\mathrm{NH}_{4} \mathrm{OH}$ solution was put in to the beaker and the top was closed with Saran wrap and a rubber band. Ammonia gas was purged $(0.2$ to 1.0 liter $/ \mathrm{min})$ through a $0.25 \mathrm{in}$. OD tubing punched 
ORNL DWG 77.2253

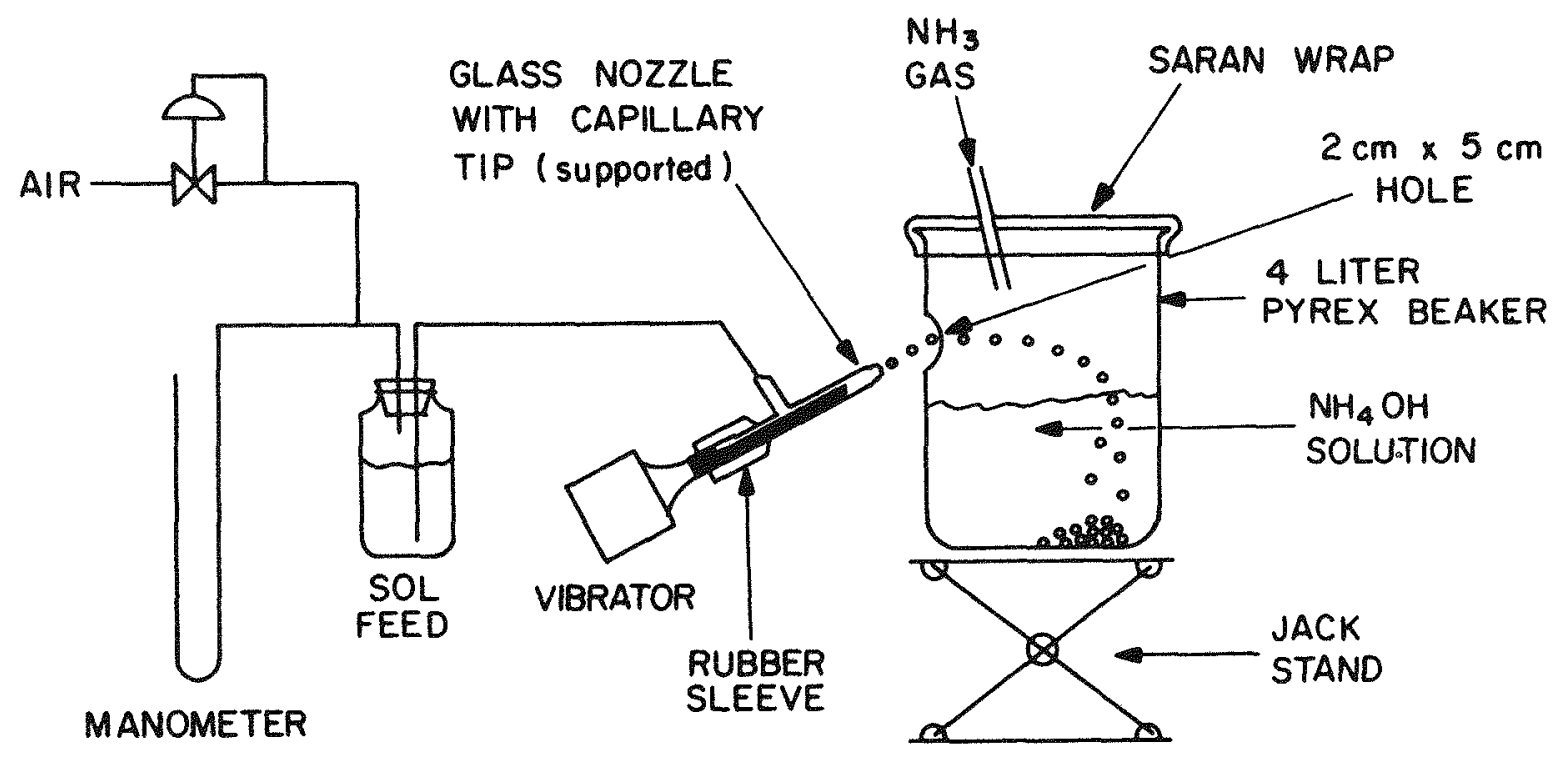

Fig. 4.1. Laboratory Equipment for External Gelation Tests. 
through the Saran wrap. The sol or broth under air pressure was fed with vibration to a capillary to form drops in air. The air pressure and the beaker level were adjusted to give the desired trajectory of drops through the hole in the breaker. A gel surface formed in the $\mathrm{NH}_{3}$ gas before the drops hit the liquid interface. After a test batch was collected and aged in the liquid, the particles were sampled for inspection and were transferred hydraulically using vacuum to the washingdrying vessel. Some tests were made with 2-ethy1-1-hexanol over an ammonia solution. Others were made with a hot plate under the four-1iter beaker to give temperature control. The aqueous ammonia usually gave a hard gel surface very rapidly so that the particles did not stick or distort as they accumulated on the bottom of the beaker.

The vertical component of the sol drop velocity is determined by gravitational acceleration and the vertical component of the sol velocity through the capillary. For gravitational acceleration starting from zero vertical velocity (a horizontal capillary or the peak of an arched trajectory) the liquid impact velocities are:

\begin{tabular}{|c|c|c|}
\hline $\begin{array}{c}\text { Time } \\
\text { (seconds) }\end{array}$ & $\begin{array}{l}\text { Downward } \\
\text { Velocity } \\
(\mathrm{cm} / \mathrm{sec}) \\
\end{array}$ & $\begin{array}{c}\text { Vertical } \\
\text { Distance } \\
(\mathrm{cm}) \\
\end{array}$ \\
\hline 0 & 0 & 0 \\
\hline 0.05 & 49 & 1.23 \\
\hline 0.10 & 98 & 4.9 \\
\hline 0.15 & 147 & 11.0 \\
\hline 0.20 & 196 & 19.6 \\
\hline 0.40 & 392 & 78 \\
\hline
\end{tabular}

For a symmetrical trajectory which starts and ends on the same level, the times are doubled. Thus an upward slanted nozzle as shown in Fig. 4.1 can easily give ammonia gas exposure times of 0.1 to 0.2 seconds (symmetrical arches of $1 / 2$ to 2 in. heights). If the drops are discharged downward into a vertical column, the column height must be much greater and the impact velocity at the liquid surface will be much higher. This difference was demonstrated experimentally. Sols which 
gave partly smashed or distorted gel particles with $60 \mathrm{~cm}$ of $\mathrm{NH}_{3}$ gas in a vertical column were successfully formed into spheres using the apparatus of Fig. 4.1.

Vibrators and nozzles developed for previous sol-gel programs at ORNL $^{1}$ were used for these studies. New glass nozzles without the drive fluid tube and with shorter tips of 0.5 to $1.0 \mathrm{~mm}$ ID were fabricated. The sol feed pressure was adjusted to control the drop trajectory. From the calculations above, it can be seen that the typical $15 \mathrm{~cm}$ horizontal distance would require capillary velocities of about $100 \mathrm{~cm} / \mathrm{sec}$. This agrees with the observed flow rates. Since a liquid jet breaks up into lengths equivalent to four jet diameters in stable natural operation, the expected frequency would be $(1000 \mathrm{~mm} / \mathrm{sec}) / 4(0.5$ to $1.0 \mathrm{~mm})$ or 500 to 250 drops/sec. These numbers agree with the observed nozzle behavior.

\subsection{EXTERNAL GELATION RESULTS FOR $\mathrm{ThO}_{2}$}

All the thoria sols tested were successfully formed by external gelation, yielding good dried gel spheres. Sol-gel processes usually give good results for pure $\mathrm{ThO}_{2}$ products as thorium gives the most stable sols, the strongest gels, and the simplest process chemistry because Th(IV) is the only valence of significance. Sphere-pac fuels do not require any large pure $\mathrm{ThO}_{2}$ spheres. Gelation tests were made with $\mathrm{ThO}_{2}$ sols to develop procedures and provide experience for use with other compositions. Sphere-pac fabrication procedures are being developed using $\mathrm{ThO}_{2}$ spheres and additional large spheres were formed for this use.

Conditions and results for formation of $\mathrm{ThO}_{2}$ gel spheres are listed in Table 4.1. The spheres formed from the General Atomic Co. hydrothermal denitration sol are now being calcined. The other samples gave densities of 9.90 to $10.02 \mathrm{~g} / \mathrm{cm}^{3}$ at sintering temperatures of 1300 to $1450^{\circ} \mathrm{C} .^{2}$

\subsection{EXTERNAL GELATION RESULTS FOR $\mathrm{ThO}_{2}-\mathrm{UO}_{3}$}

During the initial part of this report period, a limited amount of work was done with sols in the composition range 70 to $80 \% \mathrm{ThO}_{2}$ and 
Table 4.1. External Gelation Results for $\mathrm{ThO}_{2}$ Sols. Test system as shown in Fig. 4.1.

\begin{tabular}{|c|c|c|c|c|c|c|c|c|c|}
\hline \multirow{3}{*}{$\begin{array}{l}\text { Gelation } \\
\text { Test No. }\end{array}$} & \multirow{3}{*}{$\begin{array}{l}\text { Sol } \\
\text { No. }\end{array}$} & \multirow{3}{*}{$\begin{array}{c}\text { Sol } 1 \\
\text { Preparation }\end{array}$} & \multicolumn{4}{|c|}{ Sol Concentration } & \multirow{2}{*}{\multicolumn{2}{|c|}{$\begin{array}{l}\text { Gelation } \\
\text { Solution }\end{array}$}} & \multirow{3}{*}{ Results } \\
\hline & & & \multirow{2}{*}{$\begin{array}{l}\text { Th } \\
(M)\end{array}$} & \multirow{2}{*}{$\begin{array}{c}\mathrm{No}_{3} / \mathrm{Th} \\
(\mathrm{mole} / \mathrm{mole})\end{array}$} & \multicolumn{2}{|c|}{ Polymer } & & & \\
\hline & & & & & Symbol & g/liter & $\begin{array}{l}\mathrm{NH}_{4} \mathrm{OH} \\
(M)\end{array}$ & $\begin{array}{l}\mathrm{NH}_{4} \mathrm{NO}_{3} \\
\quad(M)\end{array}$ & \\
\hline 206 & 81,82 & Purchase from GAC & 3.5 & & PVA & 2.4 & 1.9 & 0 & $\begin{array}{l}\text { Good dried gel spheres, } 800 \mathrm{u} \\
\text { if theoretical density }\end{array}$ \\
\hline 209 & 83 & Purchase Erom GAC & 3.7 & & PVA & 4.0 & 1.9 & 0 & $\begin{array}{l}\text { Good dried gel spheres, } 930 \mu \\
\text { if theoretical density }\end{array}$ \\
\hline 218 & 84 & Purchase from GAC & 3.4 & & PVA & 3.2 & 1.9 & 0 & $\begin{array}{l}\text { Good wet, some cracking dried, } \\
710 \mu \text { if theoretical density }\end{array}$ \\
\hline 208 & 82 & Purchase from GAC & 3.5 & & PVA & 2.4 & 1.9 & 0 & $\begin{array}{l}\text { Slightly egg-shaped, otherwise } \\
\text { good ( } 900 \mu-\text { if dense) }\end{array}$ \\
\hline 204 & 81 & Purchase from GAC & 3.5 & & PVA & 2.4 & 1.9. & 0 & $\begin{array}{l}\text { Good dried gel spheres, } 770 \mu \\
\text { if theoretical density }\end{array}$ \\
\hline 201 & 79 & Purchase from GAC & 3.6 & & PVA & 1.0 & 1.9 & 0 & $\begin{array}{l}\text { Some particles smashed, PVA } \\
\text { concentration too low }\end{array}$ \\
\hline 190 & 76 & Purchase from GAC & 3.3 & & PVA & 3.7 & 2.5 & 2.2 & $\begin{array}{l}\text { Good wet gel spheres, }>80 \% \\
\text { cracked when dried }\end{array}$ \\
\hline 146 & 46 & Solex Run 101 & 3.0 & & PVA & 4.0 & 1.4 & 0 & Good wet and dried spheres \\
\hline 153 & 21 & $\begin{array}{l}\text { Partial } \\
\quad \text { Neutralization }\end{array}$ & 1.7 & 4.6 & None & 0 & 2.0 & 2.0 & $\begin{array}{l}\text { Good wet and dried spheres, } \\
\text { transparent }\end{array}$ \\
\hline 172 & 58 & $\begin{array}{l}\text { Partial } \\
\quad \text { Neutralization }\end{array}$ & 2.5 & 4.0 & None & 0 & 3.0 & 6.0 & Good wet and dried spheres \\
\hline 171 & 58 & $\begin{array}{l}\text { Partial } \\
\quad \text { Neutralization }\end{array}$ & 2.5 & 4.0 & None & 0 & 3.0 & 2.0 & $250 \%$ split into half spheres \\
\hline 143 & 42 & $\begin{array}{l}\text { ORNL - Thermal } \\
\text { Denitration }\end{array}$ & 2.0 & 0.11 & PVA & 6.7 & 1.0 & 0 & $\begin{array}{l}\text { Some doublets, otherwise good } \\
\text { wet and dry spheres }\end{array}$ \\
\hline
\end{tabular}


30 to $20 \% \mathrm{UO}_{3}$, with some consideration of higher $\mathrm{UO}_{3}$ concentrations of up to $50 \%$. Most sol-gel flowsheets for $\mathrm{ThO}_{2}$ can tolerate low concentrations of $U(V I)$, but the sol stability and/or gel strength decrease rapidly as the U(VI) content increases. As a result, compositions of $\geqslant 10 \% \mathrm{UO}_{3}$ require flowsheets optimized for those compositions rather than small modifications of flowsheets for $\mathrm{ThO}_{2}$. The sol-gel literature includes almost no external gelation results for 70 to $80 \%$ $\mathrm{ThO}_{2}-30$ to $20 \% \mathrm{UO}_{3}$; the only fuel cycle previously requiring this composition was recycle of ${ }^{233} \mathrm{U}$ to HTGRs.

The mixed oxide sols tested all gave weak gels as compared to similar conditions for $\mathrm{ThO}_{2}$ sols; therefore, the mixed oxide drops usually smashed, ruptured, or distorted at the $\mathrm{NH}_{4} \mathrm{OH}$ solution interface (Table 4.2). For the mixed oxide sols from partial neutralization, splits which appeared to result from swelling of the core material were also troublesome. The splits are believed to result from a combination of low gel strength and osmotic pressure effects. Addition of the organic gelation additives was of limited utility. Neither polyvinyl alcohol (PVA) nor hydroxypropyl methyl cellolose (K4M) would remain in solution for the mixed sols prepared by partial neutralization. These polymers are dissolved by hydrolysis and the high $\mathrm{NH}_{4} \mathrm{NO}_{3}$ concentrations salted out the organic compounds to give gelatinous curds. The addition of PVA to the mixed-oxide sols prepared by batch SOLEX flowsheets resulted in large amounts of a light yellow precipitate and a clear red-orange supernatant. Some mixed oxide SOLEX sols with $\mathrm{K} 4 \mathrm{M}$ added gave gel spheres of adequate quality (Table 4.2). The results varied with both the SOLEX operating conditions and the $\mathrm{K} 4 \mathrm{M}$ concentrations and additional studies would be necessary to identify the optimum conditions. The best results with mixed sols by partial neutralization were almost spheres with small splits from swelling; this type of sol merits further testing. The addition of acid-deficient uranyl nitrate (ADUN) to either SOLEX or hydrothermally denitrated $\mathrm{ThO}_{2}$ sols did not give any promising results. The sols were unstable and the gels were extremely weak. 
Table 4.2. External Gelation Results for $\mathrm{ThO}_{2}-\mathrm{UO}_{3}$ Sols. Test system as shown in Fig. 4.1.

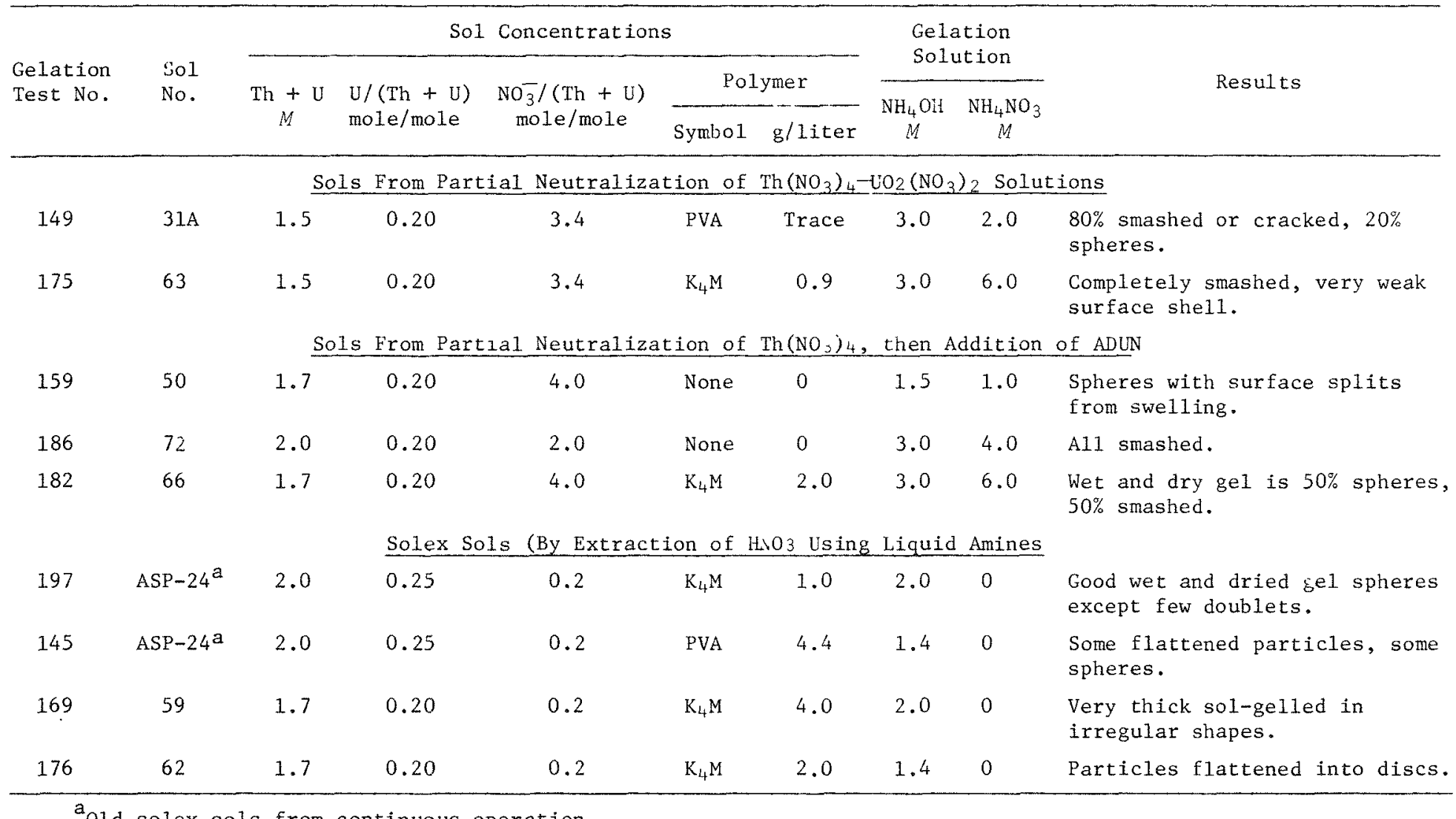


4.5 EXTERNAL GELATION RESULTS FOR UO

Successful preparation of urania spheres by external gelation of broths is reported in a number of sol-gel publications. Most descriptions of the process conditions are not very specific and product sizes of 200 to $400 \mu$ appear to be most common. Our results and the hints in the literature indicate that failures to convert the sol drops to good gel spheres have a number of characteristic causes.

1. Impact at $\mathrm{NH}_{4} \mathrm{OH}$ solution interface can distort, crush, or breakup the sphere. The strength of the gel, the degree of gelation, and the velocity of impact are all important variables.

2. Gel strength can be so low that collection and washing are not practical without damage even if impact failure is avoided.

3. Nonuniform gelation can result in hollow spheres from uranyl broths and watery voids or occlusions from some sols or broths.

4. Cracking can occur from swelling effects; perhaps as a result of osmotic pressure differences between the gel and the aqueous solution.

Gelation results for uranyl broths are summarized in Table 4.3. Attempts to reproduce the Italian SNAM broth ${ }^{3}$ resulted in a broth too viscous to be ejected through the vibrating nozzle (GT-212). Other broths close to this recipe resulted in beads that resembled pliable plastic bags (GT-215 to 217). These broths were rejected since the pliancy of the beads suggested they would not retain a spherical shape. Experimenting with the recipe led to the production of microspheres with hard she11s and mushy interiors (FT-221 and 230). The best microspheres were formed using concentrated $\mathrm{NH}_{4} \mathrm{OH}$. Addition of $\mathrm{NH}_{4} \mathrm{NO}_{3}$ to this gelating solution eliminated large splits that formed in the hard shells (GT-236 and 240). Note that drying of these microspheres leads to hollow or macroporous spheres.

Broths containing AUUN, $\mathrm{NH}_{4} \mathrm{NO}_{3}$, urea, and PVA have been used to prepare urania spheres smaller than $200 \mu$. Hollow spheres are a problem for such broths and we produced hollow spheres for our tests with similar broth compositions (Table 4.3 ). 
Table 4.3. External Gelation Results for Uranyl Broths. Test system as shown in Fig. 4.1.

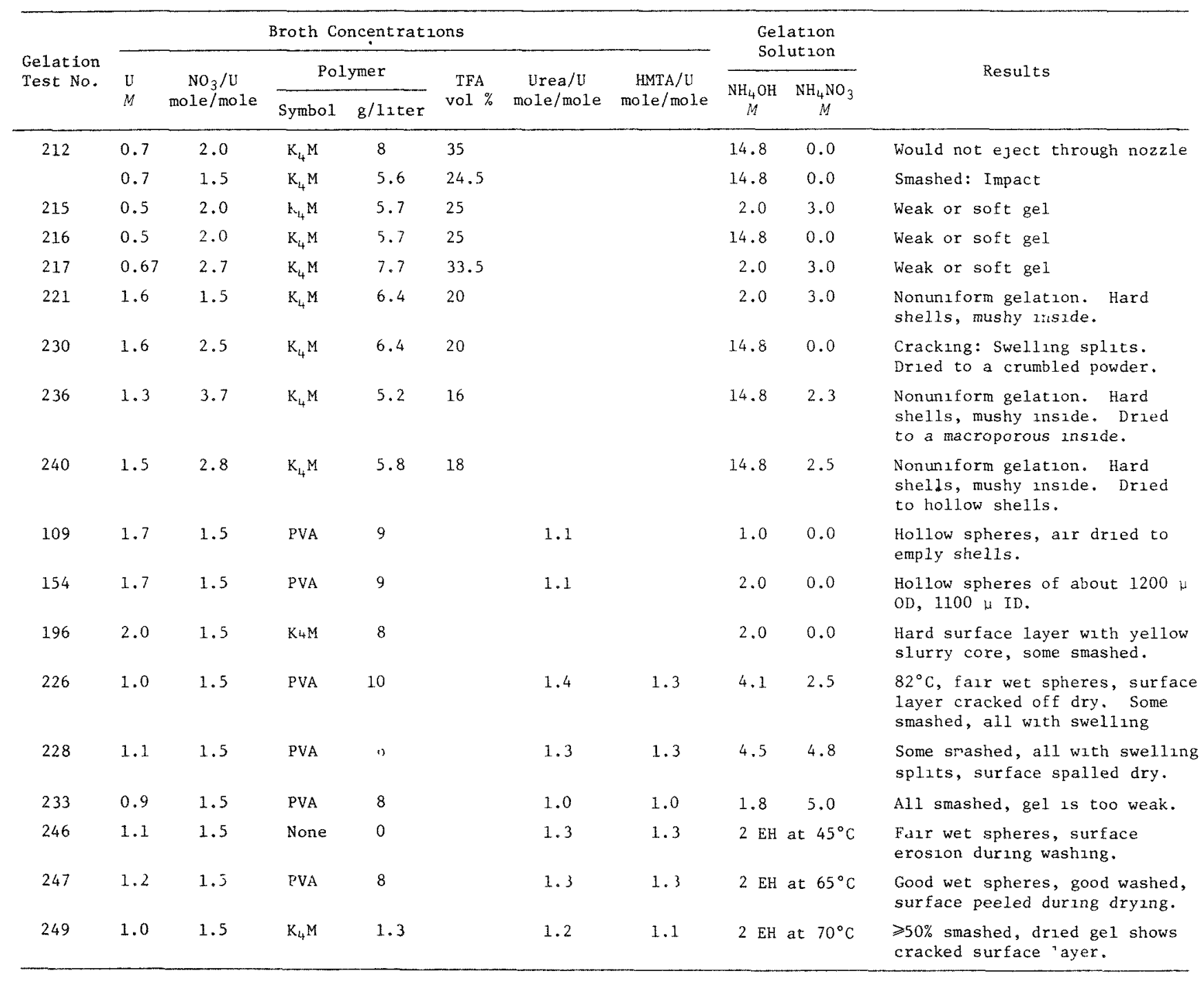


Gelation tests were made with broth compositions intended for external gelation to give a gelled surface and HMTA and urea to give internal gelation of the particle core. These tests were made with hot $\mathrm{NH}_{4} \mathrm{OH}$ solutions or hot 2-ethy1-1-hexanol over $\mathrm{NH}_{4} \mathrm{OH}$ solutions to combine the external and internal gelation effects. For $\mathrm{NH}_{4} \mathrm{OH}$ solutions, the gel particles all showed swelling type splits. The appearance suggested that the core of the particle swelled as it gelled and split the externally gelled surface. When concentrations of the broth were reduced, the particles became weak and smashed at the solution interface before the swelling effect was eliminated. Use of a 2-ethy1-1hexanol layer over an $\mathrm{NH}_{4} \mathrm{OH}$ solution layer eliminated the swelling type splits to give wet gel spheres of good appearance. This seems to indicate that the swelling resulted from uptake of water from solution during internal gelation of the drop center. These good wet gel spheres cracked very badly during drying. The appearance was that of two layers which shrink differently during drying and therefore crack. The existance of two layers can be explained by the surface layer gelling with $\mathrm{NH}_{3}$ gas and the core gelling by internal gelation. The cracking was so severe ( $100 \%$ of the particles and complete peeling of the surface layer for many particles) that elimination of cracking by minor improvements seemed unlikely. Therefore, internal gelation alone is much more promising than the combined gelation as tested above.

\subsection{REFERENCES}

1. P. A. Haas and W. J. Lackey, Improved Size Uniformity of Sol-GeZ Spheres by Imposing a Vibration on the Sol in Dispersion Nozales, ORNL/TM-4094 (May 1973).

2. Personal communication, D. P. Stinton and C. E. DeVore, Oak Ridge National Laboratory, October 1977.

3. G. Brambilla, P. Gerontopulos, A. G. Facchini, and D. Neri, "The SNAM Process for Production of Ceramic Nuclear Fuel Microspheres," in Proceedings of Symposium on Sol-Gel Processes and Reactor Fuel Cycles, Gatinburg, Tennessee, May 4-7, 1970.

4. Personal communication, H. Ringe1, Oak Ridge National Laboratory, August 1977. 


\section{WASHING AND DRYING - SUBTASK 530}

P. A. Haas, H. D. Ringel, * W. E. E1dridge,

R. C. Lovelace, and K. E. Sullivan

\subsection{INTRODUCTION}

When chemical gelation is used for sol-gel preparation of spheres, the gel must be washed to remove the $\mathrm{NH}_{4} \mathrm{NO}_{3}$ to low concentrations before it is dried and fired. Since the mass transfer inside the gel particle is controlling, the gel properties including size, composition, porosity, etc are controlling and the washing requirements are not very predictable. It is obvious that the washing equipment must provide relatively long hold-up times for the solids while the net liquid flow rate must be low to minimize waste volumes. The recommended conditions have commonly been dilute $\mathrm{NH}_{4} \mathrm{OH}\left(0.2\right.$ to $\left.2 \mathrm{MNH}_{4} \mathrm{OH}\right)$ for 0.5 to 24 hours. The minimum total wash volumes have been 4 to 10 volumes per volume of gel with the lower volumes for continuous, multiple-stage washing and the higher minimum volumes for batch washing.

\subsection{SMALL-BATCH DRYING}

For the development tests during this quarter, the washing and drying have been by simple procedures with little attention to efficiency or identifying the minimum requirements. The washing and drying have been made in $600 \mathrm{~m} 1$ Pyrex filter funnels (coarse frits) modified to attach 19/38 ground glass joints as both top and bottom connections. The particles are transferred into these vessels and the liquid is drained off. The ammonia wash solution is metered up through the bed of spheres at 30 to $50 \mathrm{ml} / \mathrm{min}$. The most common wash time was $2 \mathrm{hrs}$, but large spheres were usually soaked overnight with an additional period of washing the next day. The bed of particles is drained of liquid and then left overnight in a laboratory type drying oven set at $215^{\circ} \mathrm{C}$. About $100 \mathrm{ml}$ of water placed below the frit generates steam and limits the

\footnotetext{
*Guest scientist from Federal Republic of Germany.
} 
temperature of the particles for about one hour. The bed of particles drys slowly from the outside and the small opening in the 19/38 top joint allows escape of steam without significant exposure to air. We believe the washing and drying procedures described do not limit the product quality; that is, other washing and drying procedures would not have resulted in any significant improvements in dried gel properties.

\subsection{CONTINUOUS DRYING}

A continuous, multiple-stage moving-bed type of wash column was designed and fabricated. Good control of solids movement was demonstrated using an ion-exchange resin and water. The column is a U-shape of 2 in. ID Pyrex pipe. The wash liquid enters at the bottom of the $U$. One side is a countercurrent moving bed with the freshly formed gel entering at the top of the bed of solids with overflow of the waste wash liquid. The other, shorter side is a one-stage, cocurrent moving bed with overflow of washed gel to a collection vessel or dryer. The wash liquid that flows through this leg is pumped into the bottom inlet along with the fresh wash solution. The cocurrent water flow rate effectively controlled the resin exit rate independent of the ratio of wash water/resin in the countercurrent leg. While most gel spheres would have a higher density than the resin spheres, the same control should be practical using higher cocurrent 1iquid flow rates to compensate for the higher density. Drying of sol-gel spheres has generally required steam atmospheres with configurations to supply heat without local overheating. In some cases, chemical reactions of ammonium nitrate or organic compounds are exothermic and good heat removal is necessary to prevent cracking. Monolayers of spheres are recommended in some sol-gel 1iterature. Movingbelt type dryers are the logical design to meet these requirements for larger capacities. Therefore, we have prepared specifications and requested bids to purchase a moving-belt dryer for sol-gel processes. 


\section{MICROSPHERE SINTERING - SUBTASK 540}

D. P. Stinton, J. E. Mack, and A. E. Pasto

\subsection{INTRODUCTION}

The objective of this subtask is to produce, from the washed and dried feed provided by previous subtasks, a microsphere product capable of meeting a fuel specification. This specification is as yet incomplete but will incorporate sections on density, chemical species content, shape, size, and perhaps microstructure. The scope of this work includes development of sintering and characterization procedures which will allow control of these parameters. The primary goal is attainment of nearly theoretically dense, high purity, stoichiometric oxide spheres of several specified sizes. The optimal microstructure is not yet specified and will be defined by later irradiation tests.

The sintering program involves: (1) assessment of published literature data on sintering, (2) characterization of feed and final material, (3) sintering experimentation, and (4) interaction with sol-gel preparation subtasks to allow optimization of the feed material for sintering. During this quarter, progress was made on all four of the above elements. A computer search of literature pertaining to sol-gel microsphere processing yielded more than 300 references. The most relevant of these have been collected and are being evaluated. Results of this evaluation will be published as part of an overall sol-gel microsphere technology assessment report.

Equipment for performing sintering experiments has been identified and is being used or readied for use. Several sintering runs have been made and the materials partially characterized. Further details are provided in the following sections.

\subsection{PROCEDURES AND EQUIPMENT}

Present sintering work involves dried sol-gel particles in relatively small batches $(<1 \mathrm{~kg})$. These are subjected to shape and size analysis and sintered and recharacterized for shape, size, and density. Complete 
characterization is not performed due to time and funding limitations. However, when high density products are obtained, these are further characterized. As more sintering and characterization equipment and processes are readied, more characterization will be done. For instance, the evolution of gel support material by-products during heating will be assessed by differential thermal analysis and thermogravimetric analysis (DTA/TGA) and mass spectrometric analysis of gaseous species. This knowledge is important in evolving an optimum sintering schedule and atmosphere.

The sintering studies to date have been conducted in a $3.8 \mathrm{~cm}$-diam tube furnace with a programmable temperature controller. The furnace is operated in a controlled atmosphere. Air is used when sintering $\mathrm{ThO}_{2}$, and $\mathrm{Ar}$ and $\mathrm{Ar}-4 \% \mathrm{H}_{2}$ are used when sintering $\mathrm{UO}_{2}$ microspheres. The temperature of this furnace is increased at the desired rate by a programmer-controller to the desired temperature which can be as high as $1450^{\circ} \mathrm{C}$.

Procurement has been initiated on a similar $3.8 \mathrm{~cm}$-diam tube furnace that will operate at temperatures up to $1700^{\circ} \mathrm{C}$. It will also be capable of operating in a controlled atmosphere of air, $\mathrm{Ar}$, or $\mathrm{Ar}-4 \% \mathrm{H}_{2}$. An instrumentation and control system for this furnace has been designed and procured.

A variety of other furnace equipment is being readied for this work. Three tube furnaces of about $7.6 \mathrm{~cm}$-diam are in the process of being revamped; two of these will be complete with temperature programming controllers. A1l are capable of attaining $1450^{\circ} \mathrm{C}$ in any atmosphere. However, at this time no equipment is available for sintering large batches (several $\mathrm{kg}$ ) of spheres under controlled atmosphere in one step. This capability can be obtained in a two-step process, wherein binder and other organics can be burned out in a $20 \times 20 \times 20 \mathrm{~cm}$ air furnace, then the batch transferred to a much 1arger $(30 \times 30 \times 30 \mathrm{~cm})$ controlled atmosphere furnace. The latter furnace has been procured and should be operational in March. If binder burnout cannot be controlled in air, due to excessive $\mathrm{O}_{2}$ partial pressure, the first step may be carried out in the previously described tube furnaces. 
To date no sintering together of the particles has been observed, but this is considered a potential problem with the fines $(<100 \mu \mathrm{m})$. It may be necessary to design internals for one of the furnaces to allow a fluidizing action of the gas atmosphere through the bed.

\subsection{PARTICLE CHARACTERIZATION}

Mean particle densities of small samples of microspheres are typically obtained from water or mercury pycnometry measurements. The sample is first weighed and then placed in the pycnometer where its volume is accurately determined from the amount of liquid displaced. A measure of open porosity can also be obtained by varying the pressures at which the volume reading are taken. Sample reclamation requires rinsing and drying.

An attempt was made to utilize data obtained during a ten-minute size analysis with a particle-size analyzer (PSA) combined with the sample weight to calculate mean particle densities of small samples of sintered thoria. The PSA measurement is based on a light blockage technique. 1 The shadow created by the particle passing through a light beam is detected by a photodiode. The drop in the detector's output current is converted to a voltage gain, amplified, digitized, and stored as a single count in one channel of a multi-channel pulse height analyzer, as shown in Fig. 6.1. Particles are singularized by a rotating, evacuated drum and analyzed at rates up to 20 per second with a resolution of $0.5-2.0 \mu \mathrm{m}$ on the diameter. After the sample spectrum is accumulated, the data are transferred automatically to a computer, which generates diameter and volume distributions and calculates the means and standard deviations. Since each particle in the sample is sized, the confidence intervals around the means are sma11. The device is calibrated with a set of high-precision stainless steel microspheres (AFBMA Grade 10), with traceability to the National Bureau of Standards established through ORNL secondary standards. 
ORNL-DWG 77-11781

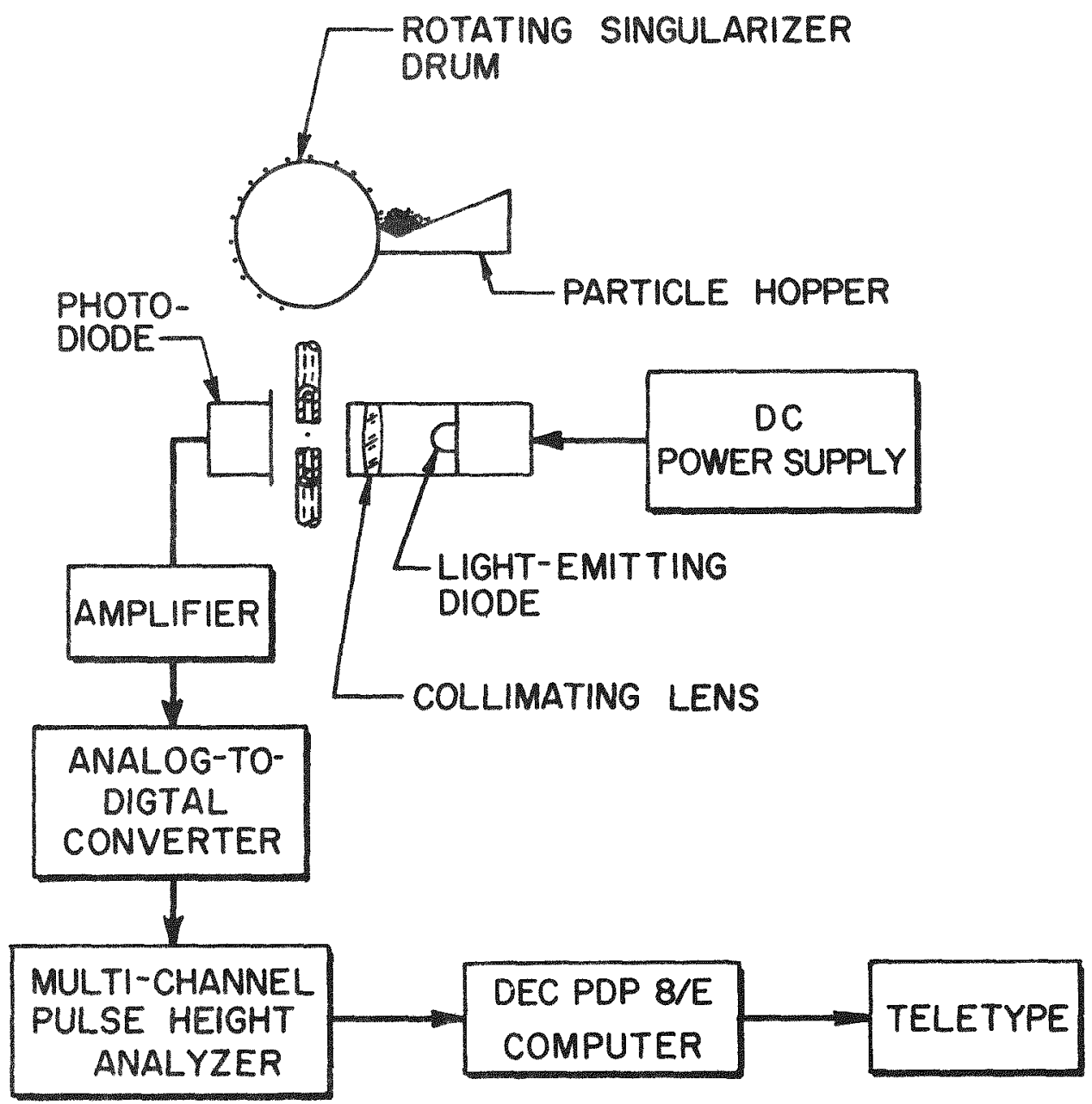

Fig. 6.1. Electronic Data Collection System for the Particle Size Analyzer. 
Mean densities calculated from the PSA data were typically higher for $\mathrm{ThO}_{2}$ spheres than those determined by water or mercury pycnometer. Visual examinations of the samples revealed a high percentage of milky, translucent particles in most of the samples analyzed. While this was found to be the cause of the discrepancy, it was noted that mean volumes calculated from readings taken from x-radiographs of the samples agreed more closely with the PSA data than with the results of the pycnometry measurements. This may have been due to the non-Gaussian size distribution and the fact that only 50 of the 110,000 particles on the radiograph are sized.

PSA density determinations on sintered urania gave values more consistent with pycnometer measurements as all of these microspheres were completely opaque. These results indicated that the particle-size analyzer would be inadequate for sizing the translucent thoria microspheres, but could be used with urania. A study is underway to determine the number of particles from a sample with a non-Gaussian size distribution which must be sized from the $x$-radiograph to adequately determine the mean diameter and volume.

\subsection{RESULTS OF SINTERING EXPERIMENTS}

Several batches of $\mathrm{ThO}_{2}$ sol-gel microspheres have been sintered in air. These runs were designed to determine the temperature required to sinter $\mathrm{ThO}_{2}$ microspheres to greater than $99 \%$ of theoretical density. The sols used to produce the microspheres were made by three processes (Solex, ORNL, and $\mathrm{NH}_{4} \mathrm{OH}$ neutralization). All microspheres were produced by external gelation. Conditions and results of these sintering runs are shown in Table 6.1 along with the pre-sintered densities of several batches. Results from these runs indicate that $1000 \mu \mathrm{m}$-diam (before firing) microspheres produced by the Solex flowsheet sinter to greater than $99 \%$ of theoretical density if heated at $300^{\circ} \mathrm{C} / \mathrm{hr}$ to about $1400^{\circ} \mathrm{C}$ and held for four hours. Microspheres $800 \mu \mathrm{m}$ in diameter sinter at a lower temperature (about $1350^{\circ} \mathrm{C}$ ) if heated in the same manner. Microspheres of $650 \mu \mathrm{m}$-diam produced by the ORNL flowsheet densify to $99 \%$ of theoretical density if heated at $300^{\circ} \mathrm{C} / \mathrm{hr}$ to $1450^{\circ} \mathrm{C}$ for four 
Table 6.1. Characterization of $\mathrm{ThO}_{2}$ Microspheres Sintered in Air.

\begin{tabular}{|c|c|c|c|c|c|c|c|c|c|c|c|c|}
\hline \multirow{3}{*}{$\begin{array}{l}\text { Sintering } \\
\text { Run } \\
\text { Number }\end{array}$} & \multirow{3}{*}{$\begin{array}{l}\text { Preparation } \\
\text { Process }\end{array}$} & \multirow{3}{*}{$\begin{array}{l}\text { PVA } \\
\text { Additions } \\
\text { (g/liter) }\end{array}$} & \multicolumn{2}{|c|}{ Sphere Diameter } & \multirow{3}{*}{$\begin{array}{c}\text { Sintering } \\
\text { Temperature } \\
\left({ }^{\circ} \mathrm{C}\right)\end{array}$} & \multirow{3}{*}{$\begin{array}{l}\text { Soak } \\
\text { Time } \\
\text { (hr) }\end{array}$} & \multirow{3}{*}{$\begin{array}{l}\text { Weight } \\
\text { Loss } \\
(\%)\end{array}$} & \multirow{3}{*}{$\begin{array}{l}\text { Volume } \\
\text { Shrinkage } \\
(\%)\end{array}$} & \multicolumn{4}{|c|}{ Particle Density $\left(\mathrm{g} / \mathrm{cm}^{3}\right)$} \\
\hline & & & \multirow{2}{*}{$\begin{array}{l}\text { Before } \\
\text { Firing } \\
\quad(\mu \mathrm{m})\end{array}$} & \multirow{2}{*}{$\begin{array}{c}\text { After } \\
\text { Firing } \\
(\mu \mathrm{m})\end{array}$} & & & & & & & Water Pycr & ometry \\
\hline & & & & & & & & & at $250 \mathrm{psi}$ & Initial & Duplicate & Triplicate \\
\hline$s-2$ & Solex & 4.0 & 800 & & 1350 & 0.5 & 4.89 & & & 9.960 & 9.972 & \\
\hline$s-3$ & Solex & 4.0 & 800 & & 1350 & 4.5 & 4.60 & & & 9.992 & 9.995 & \\
\hline$s-5$ & Solex & 4.0 & 800 & & 1450 & 3.0 & & & & 9.940 & 10.016 & 9.988 \\
\hline$s-1$ & Solex & 4.0 & 1100 & & 1160 & 2.0 & & & & 9.428 & 9.427 & \\
\hline$s-4$ & Solex & 4.0 & 1100 & & 1390 & 3.0 & & & & 9.928 & 9.972 & 9.942 \\
\hline$S-6$ & Solex & 4.0 & $1000-1100$ & 773 & 1150 & 4.0 & 4.88 & 54.76 & 6.729 & & & \\
\hline$s-10$ & Solex & 4.0 & $1000-1100$ & 690 & 1300 & 4.0 & 5.51 & 69.63 & 9.677 & & & \\
\hline$s-13$ & Solex & 4.0 & $1000-1100$ & 690 & 1450 & & & & 9.952 & & & \\
\hline$s-7$ & ORNL & 4.0 & $650-700$ & 540 & 1150 & 4.0 & 2.13 & 55.40 & 8.865 & & & \\
\hline s-11 & ORNL & 4.0 & $650-700$ & 526 & 1300 & 4.0 & 2.31 & 60.61 & 9.901 & & & \\
\hline S-14 & ORNL & 4.0 & $650-700$ & 526 & 1450 & & & & 9.961 & & & \\
\hline$S-8$ & ORNL & 6.7 & $500-700$ & 410 & 1150 & 4.0 & 2.55 & 56.80 & 9.323 & & & \\
\hline S-16 & ORNL & 6.7 & $500-700$ & 410 & 1450 & & & & & 10.000 & 9.949 & \\
\hline$s-9$ & $\begin{array}{l}\mathrm{NH}_{4} \mathrm{OH} \\
\text { Neutralization }\end{array}$ & None & $650-700$ & 476 & 1150 & 4.0 & 4.06 & 58.21 & 9.844 & & & \\
\hline$S-12$ & $\begin{array}{l}\mathrm{NH}_{4} \mathrm{OH} \\
\text { Neutralization }\end{array}$ & None & $650-700$ & 484 & 1300 & 4.0 & 4.15 & 59.16 & 9.956 & & & \\
\hline s-15 & $\begin{array}{l}\mathrm{NH}_{4} \mathrm{OH} \\
\text { Neutralization }\end{array}$ & None & $650-700$ & 484 & 1450 & & & & 9.855 & & & \\
\hline$S-18$ & General Atomic & 4.0 & 1100 & & 1450 & 4.0 & 5.39 & 47.18 & 6.788 & & & \\
\hline
\end{tabular}


hours. Microspheres $650 \mu \mathrm{m}$-diam produced by the $\mathrm{NH}_{4} \mathrm{OH}$ neutralization flowsheet densify at a temperature of $1300^{\circ} \mathrm{C}$ if heated in the above manner. Very large (1100 $\mu$ m-diam) microspheres produced by external gelation from a sol purchased form General Atomic Company did not densify significantly on initial firings to $1450^{\circ} \mathrm{C}$, but retained about $30 \%$ open porosity. A differential thermal analysis (DTA) and a thermogravimetric analysis (TGA) were run on this material to determine information about the loss of the organic additive polyvinyl alcohol (PVA) and any other information that would be helpful during sintering.

A total weight 1 oss of 5.5 wt $\%$ at $1050^{\circ} \mathrm{C}$ was observed in two temperature regimes. An initial loss ( $260 \%$ of the total) was initiated at about $60^{\circ} \mathrm{C}$ and completed by $300^{\circ} \mathrm{C}$; this corresponds to endothermic removal of adsorbed and chemisorbed $\mathrm{H}_{2} \mathrm{O}$. A second loss was observed beginning at about $400^{\circ} \mathrm{C}$, corresponding to a DTA exotherm. This 1oss region was not completed until $\sim 900^{\circ} \mathrm{C}$, at a heating rate similar to that used in the sintering studies. This weight loss is undoubtedly due to breakdown of PVA, although Levine ${ }^{2}$ finds it to occur at $300-350^{\circ} \mathrm{C}$. Based on these findings, a new sintering schedule involving a holding period at $350^{\circ} \mathrm{C}$ was devised to drive out the gaseous species at a rate which would not be disruptive to sphere integrity.

The microspheres of the above particles have been examined and are illustrated in Figs. 6.2 through 6.4. Particles produced by the Solex process and sintered at $1150^{\circ} \mathrm{C}$ [Fig. 6.2(a)] and $1300^{\circ} \mathrm{C}$ [Fig. 6.2(b)] etched differently from particle to particle within a batch. The grain size was 1 and $3 \mu \mathrm{m}$, respectively. Particles sintered at $1450^{\circ} \mathrm{C}$ etched much more evenly and had a grain size of about $10 \mu \mathrm{m}$ [Fig. 6.2(c)]. Microstructures of particles produced by the ORNL sol process and sintered at $1150^{\circ} \mathrm{C}$ [Fig. $\left.6.3(\mathrm{a})\right]$ and $1300^{\circ} \mathrm{C}$ [Fig. 6.3(b)] had very small grain sizes of about $1 \mu \mathrm{m}$. The grain size of particles sintered at $1450^{\circ} \mathrm{C}$ ([Fig. $\left.6.3(\mathrm{c})\right]$ varied from particle to particle from about 2 to $10 \mu \mathrm{m}$. Particles produced by the $\mathrm{NH}_{4} \mathrm{OH}$ neutralization flowsheet and sintered to $1300^{\circ} \mathrm{C}$ [Fig. 6.4 (a)] or $1450^{\circ} \mathrm{C}$ [Fig. $6.4(\mathrm{~b})$ ] had a grain size of about $5 \mu \mathrm{m}$. Further studies on $\mathrm{ThO}_{2}$ sintering are being deferred to allow development of a sintering schedule for $\mathrm{UO}_{2}$. 

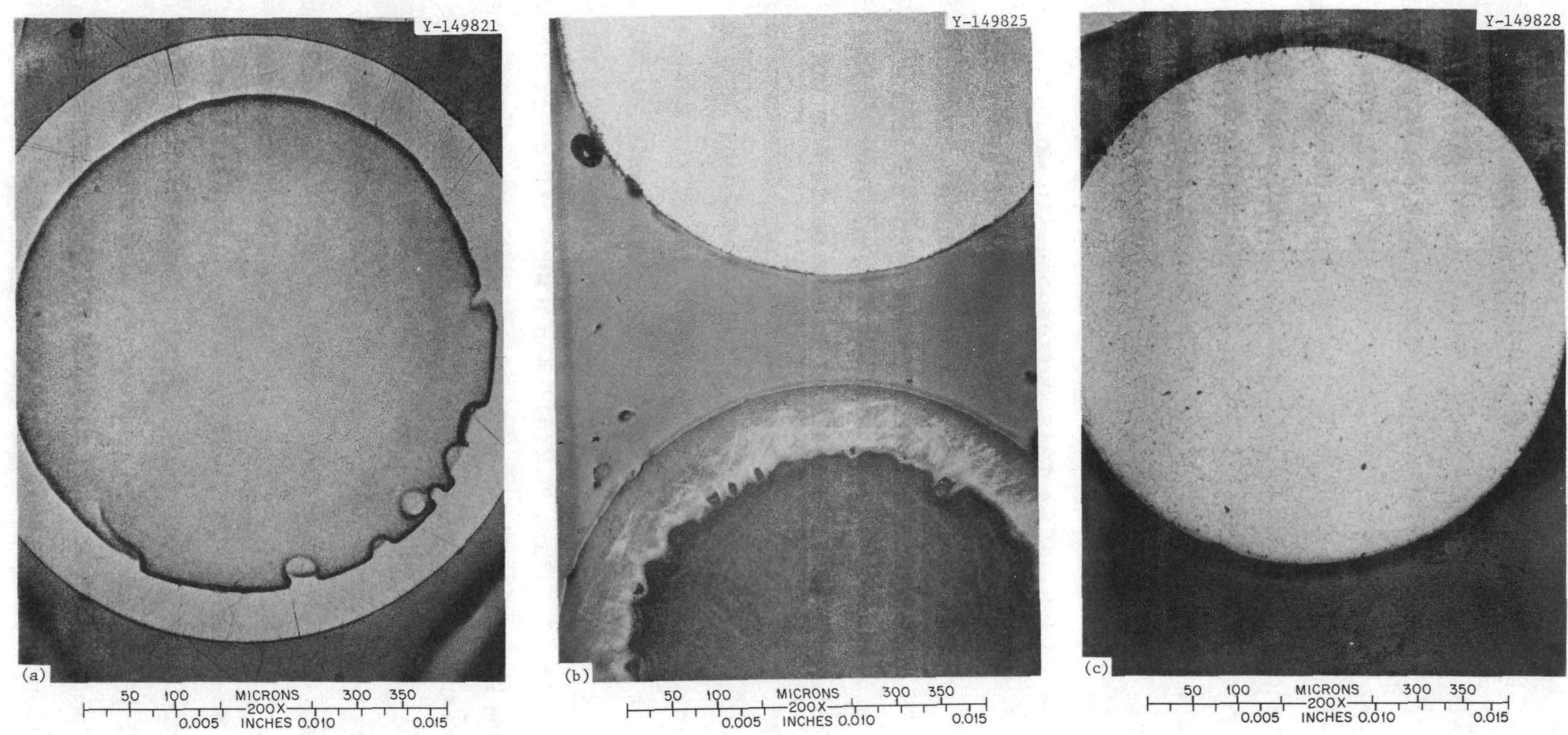

Fig. 6.2. $\mathrm{ThO}_{2}$ Particles Produced by the Solex Process and Sintered in Air at: (a) $1150^{\circ} \mathrm{C}$, (b) $1300^{\circ} \mathrm{C}$, and (c) $1450^{\circ} \mathrm{C}$. 

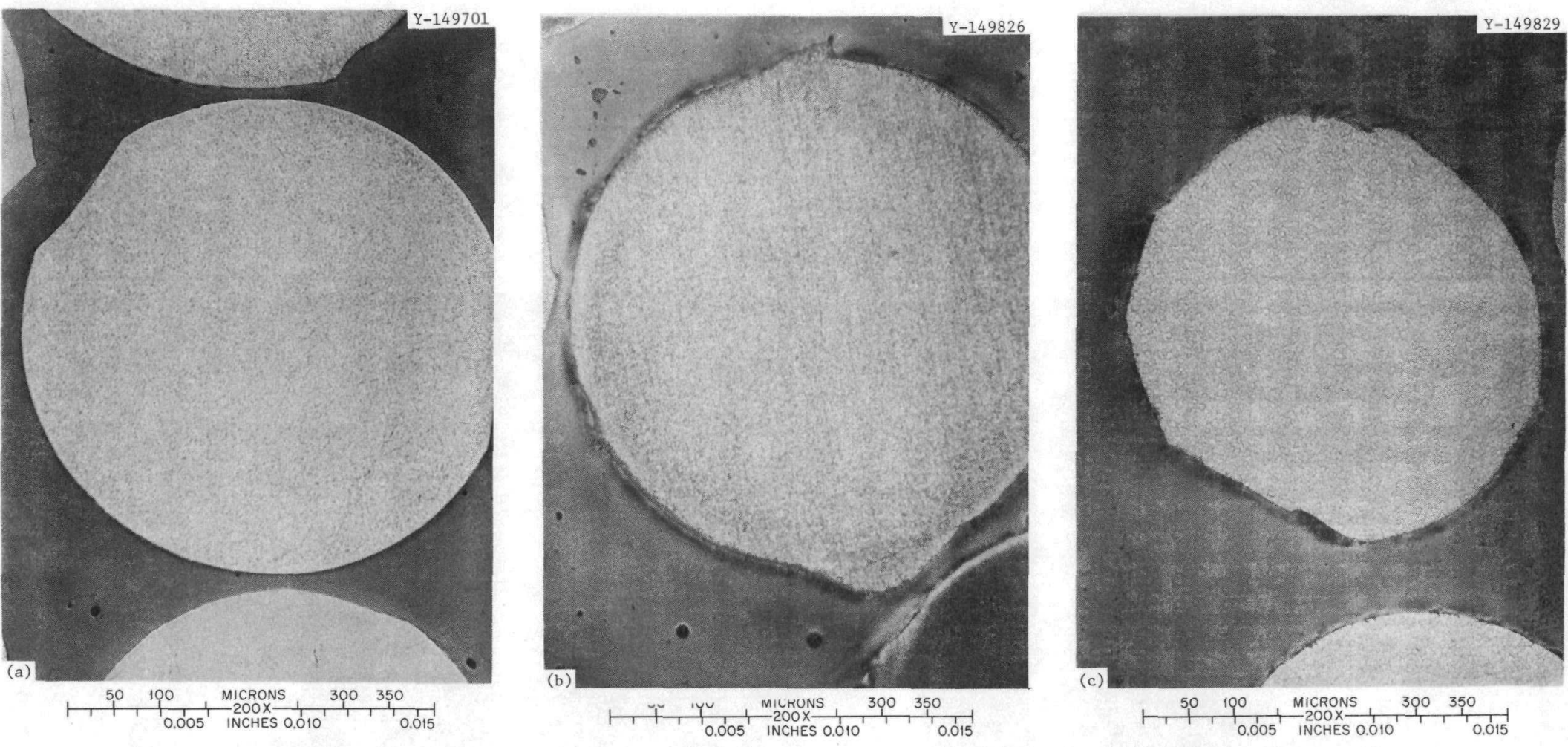

Fig. 6.3. $\mathrm{ThO}_{2}$ Particles Produced by the ORNL Sol Process and Sintered in Air at: (a) $1150^{\circ} \mathrm{C}$, (b) $1300^{\circ} \mathrm{C}$, and (c) $1450^{\circ} \mathrm{C}$. 

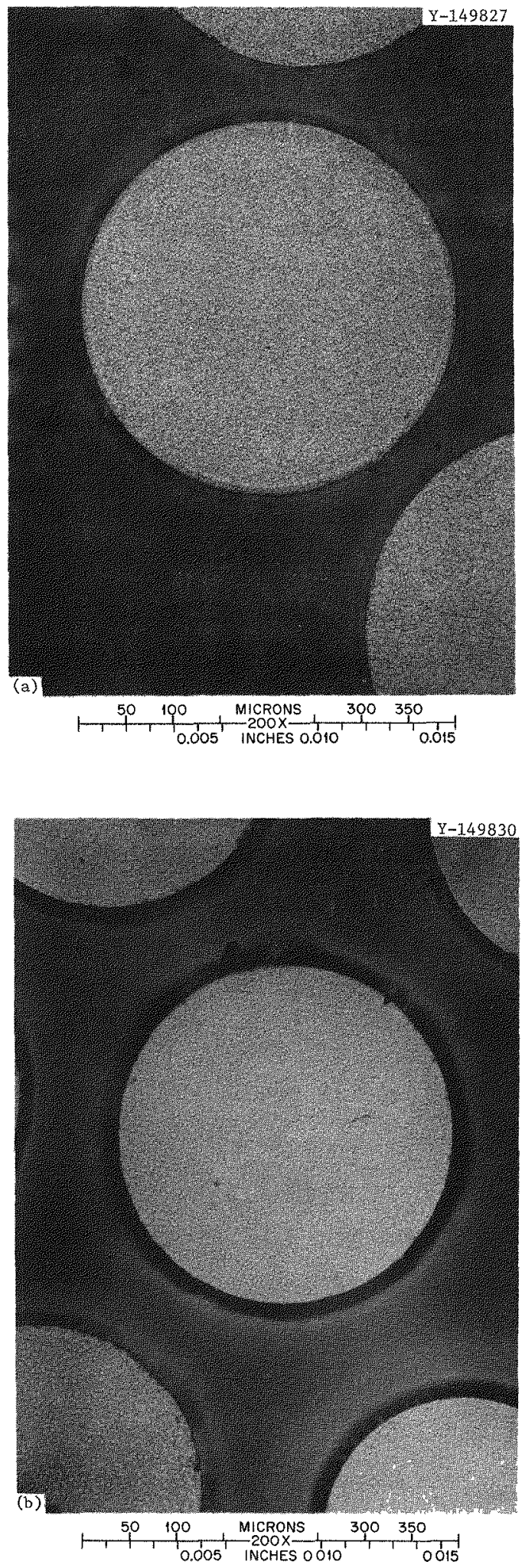

Fig. 6.4. $\mathrm{ThO}_{2}$ Particles Produced by the $\mathrm{NH}_{4} \mathrm{OH}$ Flowsheet and Sintered in Air at: (a) $1300^{\circ} \mathrm{C}$ and (b) $1450^{\circ} \mathrm{C}$. 
Efforts in ensuing quarters will be concentrated in several areas. Characterization capabilities will be upgraded by utilization of DTA/TGA and mass spectrometer equipment and determination of rapid and effective means of determining particle size and density. Several additional furnaces capable of numerous atmosphere-temperature-time regimes are being readied, which will allow more sintering runs to be made encompassing several variables in a shorter time.

\subsection{REFERENCES}

1. J. E. Mack and W. H. Pechin, Automated Particle-Size Analysis of HTGR Recycle FueZ, ORNL/TM-5907 (September 1977).

2. S. L. Levin, "A Quantitative Determination of Binder and Lubricant in Ceramic Materials by TGA," Ceramic Bulletin 48(2): 230-31 (1969).

3. P. A. Haas, F. G. Kitts, and H. Beutler, "Preparation of Reactor Fuels by Sol-Gel Processes," paper presented at AICHE National Meeting, Salt Lake City, Utah, May 21-24, 1967, CONF-670506-1.

4. B. C. Finney and P. A. Haas, "Sol-Gel Process - Engineering-Scale Demonstration of the Preparation of High-Density $\mathrm{UO}_{2}$ Microspheres, ORNL-4802 (November 1972). 
-

- 


\section{FUEL ROD LOADING - SUBTASK 550}

R. R. Suchome1

\subsection{INTRODUCTION}

The sphere-pac fabrication process involves the agitation of coarse microspheres to obtain a dense packing configuration, followed by interstitial infiltration of smaller microspheres. Development work in this subtask is focused on optimizing the packing configuration through control of particle size fractions, particle blending techniques, and particle agitation.

The simplest packing approach utilizes a batch of monosized spherical particles. In a suitable cylindrical container, a largely orthorhombic pattern is obtained; a complete orthorhombic packing would yield a density of about $61 \%$ (void volume $39 \%$ ). In practice a small amount of the more tightly packed "double stagger" structure is generated which increases the observed density to $62-64 \%$. The closest possible packing arrangement, a tetragonal structure which yields $75 \%$ density, is not geometrically stable under agitation. No single size fraction packing arrangement is even theoretically possible which will produce packing densities of $85-90 \%$ as required for fuel rods.

Whenever regular packing is present, a regular arrangement of void spaces is also present. Smaller-sized spheres could be mixed into the batch to fill these voids and thus increase the observed density. Conversely, one might add a number of extremely large spheres to the original batch of particles. In this situation, one large particle would replace a number of smaller ones as well as the voids associated with them to again increase density. The optimum "binary packing" arrangement occurs when these two effects combine to minimize void space. For spherical particles, this occurs with a mixture of about 65 vol \% coarse and $35 \%$ fine material. The precise effect of binary packing will depend on the relative sizes of the two particle types. For example, the interstitial void present amid a triangle of three closely packed 
mono-sized particles will be best filled by a sphere $0.154(\sim 1 / 7)$ the diameter of the others. Previous sphere-pac work has shown that two sizes of spheres with a diameter ratio of 4:1 will pack with an observed density of almost $73 \%$ at a mixture of $65 \%$ coarse and $35 \%$ fines. Again this technique does not provide suitable densities for nuclear fuel fabrication.

Fortunately, a mixture of three different sized particles will provide suitable densities. Proper selection of sizes and proportions of three spherical fractions should produce observed densities of up to $93 \%$. Given the restraints imposed by such factors as the narrow diameter of the cladding, long length-to-diameter ratio of the tubing, and imperfect pre-mixing, smear densities of $85-90 \%$ should still be achievable. This presumes that all of the microspheres are of theoretica? density prior to being packed into the cladding. For instance, if a $90 \%$ observed packing density is achieved with feed material which has $5 \%$ porosity (sphere density is $95 \%$ of theoretical), then the final smear density of the rod would be $(0.90 \times 0.95)$ or $85.5 \%$.

\subsection{LITERATURE REVIEW}

An initial effort in this subtask was a literature search covering past ORNL development of the sphere-pac process. Monthly and quarterly progress reports from 1966 to 1971 which described results of loading experiments conducted during that period were reviewed. Those experiments were directed toward establishing the optimum blends of the two coarse sphere fractions as well as determining the precise size ratios needed between the three sizes of spheres. Much of that work will be applicable to the current development program. Recently, the literature survey was extended to include all published literature dealing with vibratory-assisted compaction of nuclear fuel. of particular interest were descriptions of equipment used to dispense and blend the particles and to vibrate the fuel rod.

Volumetric dispensers are not essential to the loading process, but they would greatly simplify the blending operation and would enhance the reproducibility of fuel column heights and total fuel weights per 
pin. Suitable dispensers have not been developed in other sphere-pac programs, but they are currently being developed at ORNL for the HTGR (High-Temperature Gas-Cooled Reactor) Program. These dispensers have been shown to have excellent reproducibility and should be easily scalable to the volumes required for sphere-pac work.

Blending devices have received inadequate attention in past spherepac efforts. Simple techniques such as batch mixing in a ball mill container have been reported. For one program, particles were blended on a conveyor belt; the belt was fed by two vibratory feeders.

Methods for supplying vibrational input to the fuel rod have been more thoroughly investigated. Traditionally, sphere-pac work has been thought to require only low-energy vibration. Small electro-magnetic vibrators have usually been used to compact the particle beds. These devices operate at 60 or $120 \mathrm{~Hz}$ and transmit low acceleration sinusoidal input to the tube. However, considerable research has also been done on another type of particulate-based fuel element arrangement that uses shards rather than spherical particles. This type of fuel element loading technique, referred to as vi-pac, which is short for vibratorycompaction, is characterized by the use of high-energy, high-acceleration compaction devices. A number of literature reports have been found in which high-energy vibration has been successfully transferred to sphere-pac technology. A large electro-dynamic vibratory may be necessary or useful in this program to fill full-size LWR fuel rods. These vibrators have frequency ranges from 40-3000 $\mathrm{Hz}$ and can produce accelerations of up to $100 \mathrm{G}$ for sma11 payloads.

\subsection{LOADING APPROACHES}

Since three sizes of microspheres must be used to obtain a suitable density, the problem becomes one of selecting proper loading and agitation conditions as well as optimum microsphere diameter ratios. A method long used in the ceramic industry for producing a denser binary packed bed is one in which small diameter particles are infiltrated through a restrained bed of larger particles. Large diameter ratios 
are essential to the success of this technique; ratios in excess of 7 are required and in excess of 10 are preferred. It is important to note that if the bed is not restrained, particle segregation will occur; smaller particles will travel to the bottom of the bed and displace the larger spheres upward.

It is not convenient to produce sol-gel spheres in sufficiently diverse size ranges to pack three sizes using a double infiltration method. A minimum requirement might be particles $1000 \mu \mathrm{m}, 100 \mu \mathrm{m}$, and $10 \mu \mathrm{m}$ in diameter, while a better recipe would use particles having $4000 \mu \mathrm{m}, 200 \mu \mathrm{m}$, and $10 \mu \mathrm{m}$ diameters.

An alternate solution involves the use of a pre-blender to initially mix the particles prior to packing. With this technique, the need for double infiltration and thus the need for excessively large diameter ratios is eliminated. Literature reports indicate, however, that successful blending becomes more difficult as the diameter ratio between particle types increases. Earlier sphere-pac work at ORNL revealed that two particle batches could not be blended reproducibly if the diameter ratio exceeded a value of 5 . Thus, it is not expected that three sizes of spheres with widely differing diameters can be successfully pre-blended.

However, the combined use of blending and infiltration should produce fuel rods with acceptable densities, and this approach is being developed in the current program. A typical LWR fuel rod has an inner diameter of about $9.9 \mathrm{~mm}$ (0.390 in.) which sets the size of the largest particles to be loaded into it at about $990 \mu \mathrm{m}$ diam since wall effects reduce achievable density for particles greater than one-tenth the container diameter. This size of particle will be referred to as the "large coarse" and will have a diameter of 700 to $990 \mu \mathrm{m}$ depending on particle availability and tubing size. The large coarse particles will be pre-blended with another size fraction, "small coarse", prior to loading into the rod. Since microspheres of $4: 1$ diameter ratios should be adequately blendable, the small coarse is expected to have a diameter of about 150 to $250 \mu \mathrm{m}$. This blended bed will then be loaded into the rod and agitated to privide optimum packing. With this bed restrained, 
a third particle fraction, the "fines" portion, will be infiltrated into the bed. The fines fraction should have diameters of about 15 to $35 \mu \mathrm{m}$. The fuel pin must be agitated during infiltration to ensure that adequate filling of the blended coarse fraction results.

The initial loading of a single fraction coarse bed followed by a single infiltration of fines is depicted in Fig. 7.1.

\subsection{LOADING STUDIES}

A large supply of sintered $\mathrm{ThO}_{2}$ microspheres has been gathered from HTGR program storage areas, classified using available screens, and shape-separated when possible to produce a number of particle batches having mean diameters as $10 \mathrm{w}$ as $20 \mu \mathrm{m}$ and as high as $675 \mu \mathrm{m}$. Since larger diameter spheres are not yet avialable in-house, $1800 \mathrm{~g}$ of $850 \mu \mathrm{m}$-diam $\mathrm{ThO}_{2}$ spheres were purchased from General Atomic Company. With all of the above material in hand, preliminary loading studies have begun.

A laboratory-scale loading system was constructed which uses a small electromechanical vibrator. This system is being used for manual loading tests. The object of these tests is to study the effects of various sphere sizes and size distribution on the loading process. Several sections of Zircaloy tubing ( $0.380 \mathrm{in.}$. ID) have been obtained in lengths from 2 to $6 \mathrm{ft}$ for use in the laboratory-scale system.

An experimental loading study has been performed to determine the importance of various loading parameters. Sol-gel derived $\mathrm{ThO}_{2}$ spheres of $650-700 \mu \mathrm{m}$ and $35-45 \mu \mathrm{m}$ diam were loaded into a 4-ft rod using the laboratory system. There were noticeable effects of various mounting positions and feed rates on bed density, especially on the density to which the fine fraction can be compacted. Final bed densities ranged from 76.3 to $82.4 \%$ of theoretical density. A more detailed experiment of this type will be conducted soon using a blended coarse bed.

A drop test using 650-700 $\mu \mathrm{m}^{\mathrm{ThO}} \mathrm{O}_{2}$ spheres and an 11 -ft section of tubing with a closed bottom was performed to evaluate possible coarse sphere breakage during loading. After pouring the spheres into the tube ten times, on 1 y $1.7 \%$ were broken. This indicates that sphere breakage on loading full length rods is not likely to be a probelem. 
ORNL-DWG 77-10015

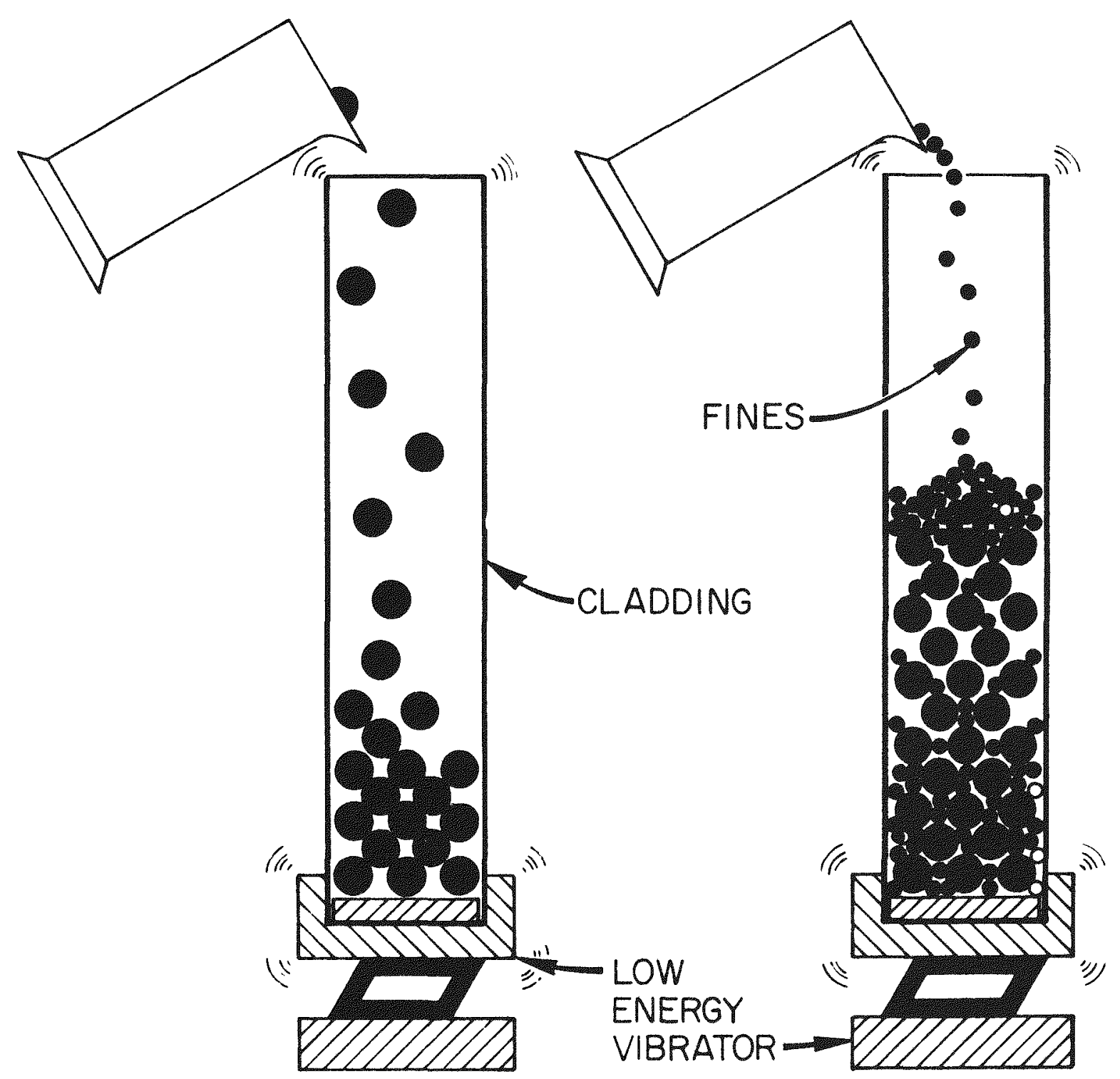

Fig. 7.1. In the Sphere-Pac Process, Low Energy Vibration of the Cladding Causes Fuel Microspheres to Assume a High Density Configuration. 
A blending technique was developed for mixing the two sizes of coarse spheres. With this technique, particles are repeatedly poured into a funnel and collected in a graduated glass cylinder. The process is repeated until an acceptable bed is noted by visual inspection. With this process, a coarse bed height of only 6-8 in. can be batch blended, but the technique is suitable for elementary loading studies in the laboratory-scale loading system and several batches can be blended to form deeper beds.

This blending procedure was used in an observation of the segregation produced during loading of a 12-ft fuel rod. By pouring a section of nominally blended coarse bed into the top of the rod and allowing it to fall through the rod into a short length of glass tubing attached to the bottom, the effects of the 12-ft free-fall were noted. It was observed that a volume of exclusively large coarse spheres, about $3 / 16$ in. in height, settled at the bottom of the rod and an approximately equal depth of small coarse spheres was found at the top of the bed. The remainder of the bed visually appeared to have remained well mixed.

Typical results of rod loadings are summarized in Table 7.1. The data show that coarse bed density improvements result from using a blended coarse bed. Failure of this improvement to be reflected in a higher overall smear density is being investigated. The most likely causes of this failure are non-optimal linkage between the vibrator and the fuel rod and use of a fine fraction with sphere diameters too large relative to the smaller coarse sphere size. Now that additional sizes of coarse microspheres are avilable, experiments will be conducted to improve the overall smear density.

\subsection{CONTINUING DEVELOPMENT}

To develop techniques for loading fuel rods 6 to $12 \mathrm{ft}$ in length, devices for dispensing and blending appropriate quantities of the various sizes of microspheres must be developed. Requirements and operating criteria for such components have been studied. A conceptual flowsheet based on the operating criteria is shown in Fig. 7.2. Work is underway 
Table 7.1. Typical Data from Rod Loadings

\begin{tabular}{ccccccc}
\hline \multirow{2}{*}{$\begin{array}{c}\text { Rod Length } \\
(\mathrm{ft})\end{array}$} & $\begin{array}{c}\text { Rod I.D. } \\
(\mathrm{in.})\end{array}$ & \multicolumn{2}{c}{$\begin{array}{c}\text { Coarse Sized } \\
(\mu \mathrm{m})\end{array}$} & $\begin{array}{c}\text { Coarse Bed } \\
(\% \text { Smear } \\
\text { Density })\end{array}$ & $\begin{array}{c}\text { Fines } \\
\text { Diameter } \\
(\mu \mathrm{m})\end{array}$ & $\begin{array}{c}\text { Infiltrated Bed } \\
(\% \text { Smear } \\
\text { Density })\end{array}$ \\
\hline 2 & 0.380 & $650-700$ & $210-250$ & 69.7 & $35-45$ & 84.8 \\
6.5 & 0.380 & $650-700$ & Not Used & 61.8 & $35-45$ & 84.8 \\
\hline
\end{tabular}

ORNL-DWG 78-1436R

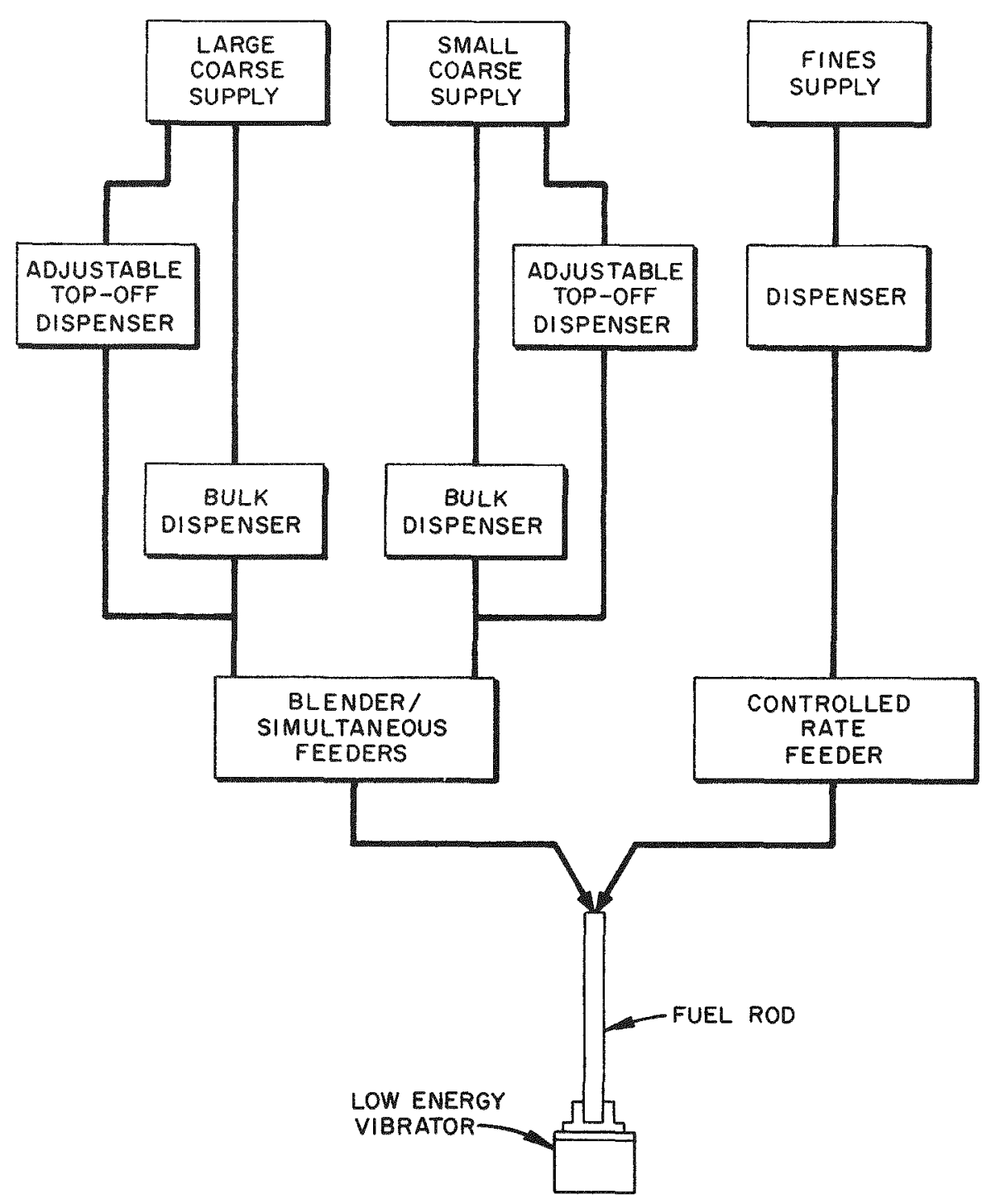

Fig. 7.2. Conceptual Flow Sheet for Sphere-Pac Rod Loading. 
to design and test methods for pneumatically transferring the fine fraction $(20-50 \mu \mathrm{m}$ diam) and for dispensing all three size fractions. Detailed design of a "fines" collection hopper is complete.

Model testing has shown that a blender concept which was adapted from HTGR development work would not be effective for blending material for sphere-pac loading. It was decided that it would not be practical to fabricate that type of blender for use with $<300-\mu \mathrm{m}$-diam spheres.

Other blending concepts currently being investigated for development include parallel feed augers, rate controllable vibratory feeders, and conveyor belt feeding. A11 of these concepts feed two parallel particle streams into a funnel where actual mixing would occur. Testing of the concepts will begin shortly.

As a result of the literature survey, it was determined that compaction of full-scale (12-14 ft) fuel rods may require larger driving forces. Vendors have been contacted to determine the availability and price of large electrodynamic vibrators for this process. These vibrators should be capable of producing oscillations over a range of frequencies and a range of accelerations so that the loading process can be optimized. A specification for such an electrodynamic vibration system has been completed.

A loading experiment is in progress to determine the exact mixture of large and small coarse material which provides the best base for infiltration of fines. Also the diameter ratio of the materials comprising the blended bed is being varied to determine the importance of this variable.

Most of the microspheres presently on hand are left over from earlier programs and lack precise size control. Since new sol-gel technology is available which offers improved size control, it will be of interest to compare results using material with the same mean diameters but having different relative standard deviations. Such experiments will be performed as new supplies of spheres are made and sintered. 
-

- 
8. FUEL ROD INSPECTION - SUBTASK 560

J. E. Mack, P. Angelini, and S. P. Baker

\subsection{INTRODUCTION}

Two characteristics of primary interest in the loading of fuel rods by the sphere-pac method are: (1) the density of heavy metal within the rod and (2) the homogeneous distribution of the heavy metal throughout the length of the fuel rod. Fuel rods fabricated by this technique will be required to meet stringent specifications comparable to those on pellet fuel rods on these characteristics. Consequently, a nondestructive highprecision measurement technique is required. Such a device is also of use in controlling the loading process. The device will be an integral part of both the loading and inspection systems. It will be used to monitor and control the dispensing and packing of the fuel microspheres as well as to determine the final height and density variations of the packed fuel rod. Criteria for a gamma attenuation device to serve this dual function have been developed, and fabrication of a laboratory-scale system is underway as described below.

Future applications will include use of the device to measure the actual density at any point in the rod. The measurement technique may also be utilized in assaying the fissile content of fuel rods.

\subsection{LOADING LEVEL AND DENSITY DETERMINATION}

In developing criteria for a device to be used in both the loading and inspection of sphere-pac fuel rods, the following objectives were identified. The control of the final loading level of the fuel rods must be an automatic, closed-1oop operation between the trimming volumetric dispensers and the level determining device. The loading level of both the coarse and fine microspheres must be tracked. Finally, the packed bed density as a function of fuel rod height must be determined. 
The technique employed is based on the detection of gamma rays attenuated by the fuel rod. A detector assembly, consisting of a gamma source, collimator, and detector, is moved along the axis of the fuel rod to either track fuel loading or measure density. The output of the detector decreases as the assembly is moved from a region of low density to a region of high fuel density due to the increased attenuation. A translational motor drive with variable speed control and encoder moves the detector assembly along the fuel rod and monitors its position. A microprocessor is used to control the sequence of operations which the device is to perform.

The detector assembly, translational motor, and microprocessor constitute the feedback control 1oop. The output of the detector is analyzed by the microprocessor which controls the speed and direction of the drive motor which in turn repositions the detector. During loading of the fue1 rod, the detector assembly tracks the fuel bed height as the rod is filled. The drive motor is made to speed up, stop, or reverse, depending on the microprocessor's analysis of the detector's output signal. In measuring density variations within the loaded fuel rod, the microprocessor drives the motor at a constant speed. It simultaneously monitors the detector's output and performs calculations based on the strength of the signal to generate a density profile for the packed bed. The versatility of the microprocessor also permits the different variables to be combined in the output to the digital plotter, such as giving fuel density as a function of rod height and packed bed height as a function of time.

The detector assembly must translate in the vertical direction when following the fuel loading level. In order to have a rapid response to level changes, the detection assembly should have low mass to minimize inertia. The device has been designed to use a gamma-ray radioisotope source and a "ruggedized" sodium-iodide detector. The maximum scan speed to which the present device should operate is $6 \mathrm{ft} / \mathrm{min}$. A study was performed using typical densities of materials to be loaded in order to determine the optimum photon energy necessary in the photon attenuation method. An. experiment was performed to verify the calculations. Short 
rods containing coarse particles and fines were fabricated. A radioactive isotope of Lutetium $\left({ }^{\left.177 \mathrm{~m}_{\mathrm{Lu}}\right)}\right.$ was determined to be the optimum gamma source. The optimum source strength was also calculated and verified. A set of radioisotope sources have been ordered and fabricated. Based on the source strengths a shield assembly was designed to reduce the radiation to a safe level. The shields, designed to surround both the source and the detector, have been fabricated. The source capsules are fabricated from $\mathrm{Ta}-10 \% \mathrm{~W}$ and the shield and collimators from tungsten. Two types of collimators were fabricated, one with a 2-mm-diam hole and one with a $1 \mathrm{~mm} \times 3 \mathrm{~mm}$ rectangular sit.

The mechanical support assembly of the lab-scale fuel level and density determining device has been designed, fabricated, and assembled. The unit will scan a 2-ft length. Design of the engineering-scale device has also been initiated. The unit will have a scan range of over $6 \mathrm{ft}$ and be adaptable to a 12-ft range.

\subsection{FUEL ROD INSPECTION INSTRUMENTATION}

The instrumentation and control system for the level and density determining device has been designed. The control system consists of a closed-loop dc-servo motor positioning system, a microprocessor controller, a single channel analyzer (SCA) with timer-counter, and a digital plotter as illustrated by the block diagram in Fig. 8.1. These items were ordered, and all have been received with the exception of the positioning system.

Diagrams for the wiring of the microprocessor controller I/O cards are nearing completion. Additional capability for the microprocessor controller in the way of stepping motor drive interface cards have been ordered. This capability permits very accurate closed-loop control of the final loading level of sphere-pac rods. The instrumentation required for the three automatic trimming dispensers has been determined and the necessary parts have been ordered. 
ORNL-DWG 77-18894

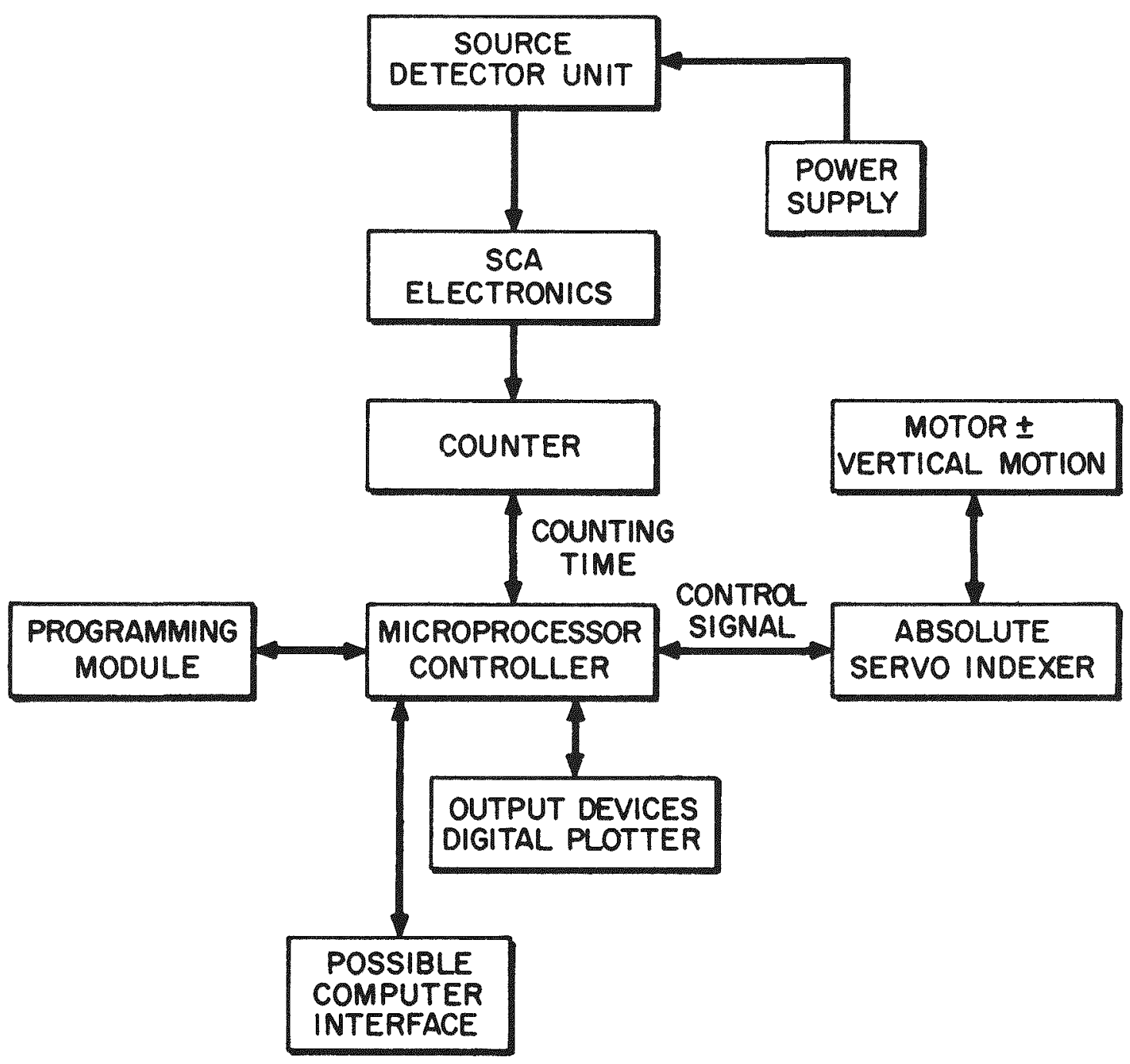

Fig. 8.1. Block Diagram of Device for Determining the Loading Level and Density of Sphere-Pac Fuel Rods. 


\section{INTERNAL DISTRIBUTION}

ORNL/TM-6746

Distribution

Category UC-77

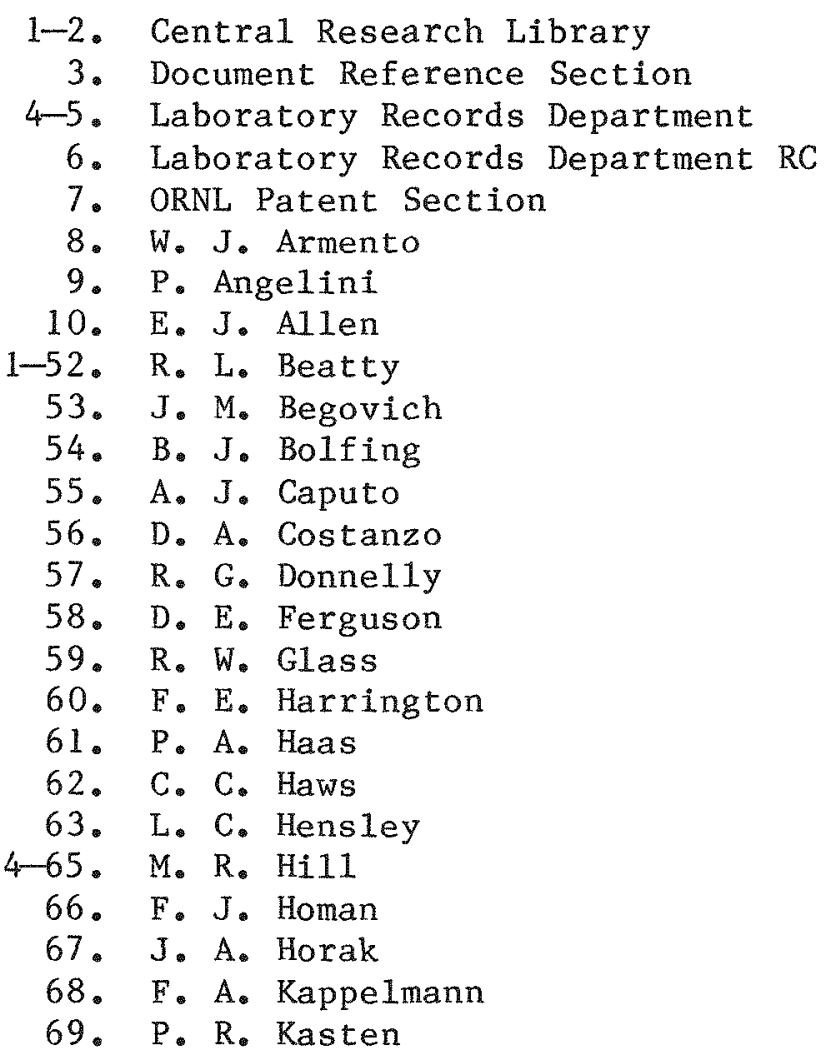

70. R. K. Kibbe

71. J. J. Kurtz

72. W. J. Lackey

73. R. E. Leuze

74. M. H. Lloyd

75-76. A. L. Lotts

77. J. E. Mack

78. D. E. McE1roy

79. R. E. Norman

80. K. J. Notz

81. A. E. Pasto

82. A. D. Ryon

83. T. F. Scanlan

84. C. D. Scott

85. W. D. Simpson

86. R. D. Spence

87. D. P. Stinton

88. R. R. Suchome1

89. V. J. Tennery

90. S. M. Tiegs

91. D. B. Trauger

92. J. S. Vavruska

93. J. R. Weir

94. D. F. Williams

95. R. G. Wymer

EXTERNAL DISTRIBUTION

96-97. DOE DIVISION OF NUCLEAR POWER DEVELOPMENT, Washington, DC 20545 Director

98. SAN-DEVELOPMENT, SAN DIEGO AREA OFFICE, P.O. Box 81325, San Diego, CA 92138

Senior Program Coordinator

99. DOE SAN FRANCISCO OPERATIONS OFFICE, 1333 Broadway, Wells Fargo Building, Oakland, CA 94612

Manager

100. DOE OAK RIDGE OPERATIONS OFFICE, P.O. BOX E, Oak Ridge, TN 37830

Assistant Manager, Energy Research and Development

101-276. DOE TECHNICAL INFORMATION CENTER, P.0. Box 62, Oak Ridge, TN 37830

For distribution as shown in TID 4500 Distribution Category, UC-77 (Gas-Cooled Reactor Technology) 